\title{
A GLACIAÇÃo PLISTOCÉNICA DA SERRA DO GERÊS
}

\author{
ANTÓNIO DE BRUM FERREIRA ${ }^{1}$ \\ JUAN RAMÓN VIDAL ROMANí ${ }^{2}$ \\ JOSÉ LUÍS ZÊZERE ${ }^{3}$ \\ MARIA Luísa RoDRIGUes 4
}

\begin{abstract}
Resumo - Estudos anteriores de Schmidt-Thomé (1973, 1978) e de Coudé-GAussen $(1978,1979,1981)$, que defendiam a existência de uma glaciação plistocénica na Serra do Gerês, provocaram viva controvérsia. Os autores do presente artigo retomaram o assunto, seguindo duas vias complementares: 1) levantamento sistemático de campo; 2) análise laboratorial dos depósitos, nomeadamente o estudo micromorfológico dos sedimentos subglaciários. A análise destes últimos revelou-se de importância fundamental no diagnóstico seguro de outros vestígios glaciários. Confirma-se a glaciação na Serra do Gerês, que terá atingido maior amplitude nos sectores de Couce, vale da Ribeira das Negras e depressão de Compadre. A descoberta de novas moreias altas e a identificação de sedimentos subglaciários permitiram reconstituir uma cúpula de gelo com $150 \mathrm{~m}$ de espessura, tanto no Couce como em Compadre, e os depósitos subglaciários permitiram precisar melhor os limites das línguas glaciárias periféricas. Dados recentes de cronologia absoluta, baseados nos isótopos cosmogénicos gerados em superfícies polidas glaciárias, sugerem que a fase pleniglaciária geresiana é anterior à Última Glaciação.
\end{abstract}

Palavras-chave: Glaciação plistocénica, moreias e sedimentos subglaciários, Noroeste da Península Ibérica.

Abstract - The pleistocene Glaciation of Serra do Gerês (Northwest PortuGaL) - Studies made by Schmidt-Thomé $(1973,1978)$ and Coudé-Gaussen (1978, $1979,1981)$ which put forward the explanation of a Pleistocene glaciation in the Gerês mountain gave rise to lively controversy. In order to clarify the problem, the authors of the present study selected two lines of research: 1) detailed geomorphologic mapping; and 2) laboratory analysis of the glacial deposits. This sedimentological study, which had not been carried out before in the area, proved to be very significant for the diagnosis of the style and extent of the glaciation. We can

1 Investigador do Centro de Estudos Geográficos, Professor Catedrático da Universidade de Lisboa (endereço do CEG no início do volume).

2 Catedrático de Geodinâmica da Universidade de Corunha. Instituto Universitario de Xeoloxía Isidro Parga Pondal. Campus de A Zapateira s/n 15071 A Coruña, España.

3 Investigador do Centro de Estudos Geográficos, Professor Auxiliar da Universidade de Lisboa. E-mail: jlzezere@mail.telepac.pt

4 Investigadora do Centro de Estudos Geográficos, Professora Auxiliar da Universidade de Lisboa. E-mail: luisa.rodrigues@mail.telepac.pt 
confirm the Serra do Gerês glaciation. The vestiges are particularly clear and important on the Eastern side of the mountain and in the Fafião Valley, where the most important glacigenic sediment complex is found. At the glaciation maximum, an ice dome reached the thickness of some $150 \mathrm{~m}$ in both the Couce and the Compadre areas, from whence outlet glaciers radiated into the main peripheral valleys. At that time the upstream sector of the Homem Valley glacier must have reached the thickness of about $300 \mathrm{~m}$. Recent absolute dating, using cosmogenic isotopes in glaciated granitic surfaces, suggest that the glaciation maximum in the Gerês is older than the Last Glaciation.

Key words: Pleistocene glaciation, moraines and subglacial tills, Northwest Iberian Peninsula.

\section{O PROBLEMA E A METODOLOGIA}

A primeira referência a uma possível glaciação da Serra do Gerês deve-se a JoRGE (1888), hipótese brevemente discutida por CHOFFAT (1894). Mais de meio século depois, GutiérRez SANCHez (1957) fala, vagamente, da existência de depósitos glaciários na vertente galega (Serra de Xurés) e GIRÃo (1958) descreve alguns aspectos da morfologia da área do Couce que lhe parecem indicar origem glaciária. A publicação deste último trabalho veio contrariar a posição normalmente assumida no meio científico nacional, defendida nomeadamente por LAUTENSACH (1929), ou seja: a baixa altitude das montanhas do Minho, bastante inferior ao limite das neves perpétuas calculado para a Serra da Estrela $(1650 \mathrm{~m})$, não permitiria supor a existência, nelas, de vestígios da glaciação plistocénica.

O assunto só viria a ser tratado de maneira sólida, com bases científicas, cerca de vinte anos mais tarde, nos trabalhos de Schmidt-Thomé $(1973,1978)$ e de Coudé-Gaussen $(1978,1979,1981)$. Embora esses trabalhos tenham aparecido sensivelmente na mesma altura, as investigações desses dois autores decorreram de forma independente. Apesar de coincidentes na afirmação da existência de uma glaciação plistocénica na Serra do Gerês, as interpretações dos dois autores divergem em muitos pontos. Schmidt-Thomé defende uma glaciação muito ampla na vertente galega, onde uma moreia terminal teria atingido a altitude incrivelmente baixa de 450 m (SснміDт-Тноме́, 1978, p. 228). No que se refere ao território português, o glaciar do vale do Homem teria atingido a altitude de $600 \mathrm{~m}$ e uma espessura, a montante, da ordem dos $500 \mathrm{~m}$. Coudé-Gaussen não estudou a vertente galega, mas alargou as suas investigações para oriente, na área de Compadre, e para sul, no alto vale do Fafião, onde encontrou vestígios importantes da glaciação. Segundo a autora, a glaciação do vale do Homem é bem mais restrita do que a referida por SchmidtThomé, mas defende, pelo contrário, a existência de uma calote de planalto que atingiria na parte oriental do Gerês uma espessura de $150 \mathrm{~m}$.

Esses trabalhos tiveram um acolhimento muito diverso na comunidade científica peninsular e deram origem a viva controvérsia. Alguns autores, nomea- 
damente em Portugal, aceitaram sem reservas os principais resultados desses estudos (Carvalho e Nunes, 1981; Moreira e Ramos, 1981; Daveau, in Coudé et al., 1983; DaVEaU e Devy-Vareta, 1985), enquanto outros negaram formalmente a existência da glaciação (Teixeira e Cardoso, 1979; Martínez de Pisón e ARENILlas Parra, 1979, 1984).

A morfologia glaciária da Serra do Gerês está longe de apresentar a nitidez de que ela se reveste nos Pirenéus e na Cordilheira Central ibérica, incluindo a Serra da Estrela. Três características da montanha geresiana contribuem para a dificuldade de indentificação dos vestígios da glaciação: 1) a homogeneidade do substrato, de composição granítica, dificulta o estudo das trajectórias dos depósitos, além de que as características estruturais dos granitos originam um modelado que se pode confundir com formas e depósitos de origem glaciária, nomeadamente no caso das moreias; 2) as características topográficas, com declives muito fortes, dão origem ao transporte gravítico de grandes blocos, os quais se podem confundir facilmente com os blocos erráticos, transportados pelos glaciares; pelas mesmas razões, as moreias dos vales não conservaram a sua forma depois da fusão glaciária, tendo-se deslocado ao longo das vertentes mais íngremes, por simples acção da gravidade ou com a participação de processos periglaciários; 3) a elevada torrencialidade pós-glaciária, devida aos fortes declives, à elevadíssima precipitação e à degradação antrópica da vegetação, não favoreceu a conservação dos depósitos glaciários e deu origem a acumulações grosseiras que podem confundir-se com as acumulações fluvioglaciárias. Poderia juntar-se ainda, no sentido de melhor compreender as dúvidas geradas em torno da glaciação do Gerês, a difícil acessibilidade desta montanha, longe dos percursos habituais dos cientistas interessados no glaciarismo ibérico.

Foi nestas circunstâncias que os autores do presente artigo resolveram retomar o assunto. $\mathrm{O}$ tema era de importância, pois a confirmação da existência de uma glaciação, de baixa altitude, na montanha do Gerês, teria necessariamente implicações na definição das condições paleoambientais plistocénicas do Noroeste da Península Ibérica. Utilizaram-se duas vias de investigação complementares: 1) por um lado, o levantamento sistemático, no campo, das formas e depósitos, tanto glaciários como periglaciários, com cartografia nas escalas de 1:5 000 ou de 1:10 000 nos lugares de maior riqueza e complexidade; 2) por outro lado, a análise laboratorial dos depósitos, nomeadamente o estudo micromorfológico dos depósitos subglaciários. A identificação, no campo e no laboratório, dos depósitos subglaciários, método não utilizado em investigações anteriores, revelou-se de grande importância na definição dos limites da glaciação e constituíu um auxiliar por vezes imprescindível no diagnóstico seguro de outros vestígios de características equívocas.

Os trabalhos de campo decorreram em diversas campanhas de Verão, entre 1986 e 1991. Grande parte dos resultados obtidos foram publicados em Espanha, nos artigos de Vidal Romaní et al. (1990 b) e de FERREIRA et al. (1992). 
Recentemente foi elaborado um trabalho mais desenvolvido, mas de difusão relativamente restrita (FERREIRA et al., 1999), incluído nas séries de Relatórios do Centro de Estudos Geográficos. O presente artigo retoma os aspectos mais salientes deste relatório, com vista a uma mais ampla difusão dos principais resultados alcançados.

\section{ASPECTOS GERAIS DA GEOMORFOLOGIA DA SERRA DO GERÊS}

A Serra do Gerês faz parte do maciço granítico da Peneda-Gerês, de instalação hercínica tardia, em que domina um granito porfiróide de grão médio a grosseiro, designado por granito do Gerês. De acordo com Dias et al. (1998), o granito do Gerês ter-se-á instalado há $296 \pm 2$ Ma. Em áreas restritas aflora na Serra do Gerês um granito de grão fino biotítico, o denominado granito de Carris. Em faixas de cisalhamento ocorrem os chamados granitos vermelhos, que foram sujeitos a um fenómeno de epissienitização por acção hidrotermal, que transformou os granitos em rochas constituídas essencialmente por feldspatos rosados e minerais verdes (MARTINS, 1972; Noronha e Ribeiro, 1983).

A Serra do Gerês é uma montanha cortada por vales profundos, com vertentes muito abruptas, que podem atingir várias centenas de metros de altura. Esses vales encontram-se instalados por via de regra em fracturas tardihercínicas. O exemplo mais espectacular é o vale dos rios Gerês e Caldo, que segue uma falha em desligamento, de direcção NNE-SSW. Os interflúvios são geralmente pouco amplos, onde mal se conservam os restos dos aplanamentos terciários. Os cimos da montanha apresentam retalhos planos em torno dos 1400-1450 m. As altitudes vão depois descendo para sul, por patamares em geral mal definidos, atingindo-se a altitude aproximada dos $500 \mathrm{~m}$, junto do vale do Cávado.

Na Serra do Gerês observa-se um contraste acentuado entre as áreas mais altas e que foram sujeitas à glaciação, geralmente de rocha nua, e as áreas não afectadas pela glaciação, onde se encontra uma típica morfologia de alteração granítica. Esta última conserva os restos dos saprólitos terciários e apresenta relevos residuais ou Inselberge, no sentido que lhe é dado por Twidale (1982), quer sejam de tipo Bornhardt, ou cúpulas rochosas, ligadas à desagregação granular e à exfoliação, que no Gerês tomam a designação de medas, quer de tipo Castle Kopje (ou Castle Koppie), relevos acastelados, ligados a sistemas de fracturas ortogonais, designados no Gerês por borrageiros (VIDAL Romaní, 1989; VIDAL Romaní et al., 1990 a). Mais frequentes do que as medas e borrageiros, são os Tor, formas mais pequenas, não ultrapassando normalmente a dezena de metros de altura, e que são constituídas por um empilhamento de blocos in situ, geralmente arredondados, prefigurados no perfil de alteração, e postos em evidência pela erosão diferencial entre o rególito e a rocha sã. Da destruição dos tors resultam as bolas graníticas, que se amontoam ou se espalham pelas 
vertentes, constituindo os chamados caos de bolas.

III. VESTÍGIOS GLACIÁRIOS E PERIGLACIÁRIOS

\section{Ausência de uma típica morfologia glaciária}

As terras altas da Serra do Gerês, afectadas pela glaciação plistocénica, estão longe de apresentar as características típicas de um planalto glaciário, com dorsos rochosos alternando com depressões preenchidas por lagoas, charcos ou turfeiras. $\mathrm{O}$ melhor indicador dos limites das áreas glaciadas, tal como acontece na Serra da Estrela (LAUTENSACH, 1929; DAVEAU, 1971), embora aqui a morfologia glaciária seja bastante mais nítida do que na Serra do Gerês, é o contraste entre a paisagem de rocha nua, varrida pelos glaciares, e a paisagem de alteração gnanítica, com restos de saprólitos, tors e caos de bolas.

Verificou-se na Serra do Gerês que, não só as formas maiores do modelado granítico, como as cristas rochosas, medas, borrageiros e tors, mas também formas menores, como as pias (termo galego que designa as gnammas), são anteriores à glaciação. Na realidade, estas encontram-se parcialmente destruídas nas áreas afectadas pelos glaciares e só aparecem plenamente desenvolvidas fora dos limites da glaciação. Apenas as formas secundárias, nomeadamente as que resultam da degradação das pias, podem ter uma evolução relativamente rápida, e serem assim pós-glaciárias (VIDAL Romaní et al., 1990 a).

Também as formas embutidas no planalto não apresentam, na generalidade, uma morfologia tipicamente glaciária. Existem apenas dois grandes circos glaciários com formas clássicas, em anfiteatro, o de Cocões de Concelinho, no vale de Couce, e o da cabeceira da Ribeira das Negras (fig. 1). Muitas outras cabeceiras largas deverão ter funcionado como circos, tal como se deduz pela associação dessas formas com os depósitos glaciários, mas elas não apresentam uma clara morfologia glaciária. O mesmo se passa com a maioria dos vales glaciários, onde, ao contrário do que acontece por exemplo na Serra da Estrela, não se encontra a típica alternância de covões (os ombilic) e de ferrolhos (os verrou). A maior parte dos vales percorridos pelas línguas glaciárias apresentam vertentes de perfil rectilíneo ou ligeiramente côncavo, regularizadas pelos processos periglaciários.

\section{As moreias}

Devido ao forte declive das vertentes, a maior parte das moreias laterais foram destruídas, aquando da fusão das línguas glaciárias, devido, como se referiu, à acção da gravidade pura ou associada a processos solifluxivos periglaciários (fot. 1). Na Serra do Gerês, as moreias apresentam-se como acumulações pouco espessas de blocos arredondados, resultantes da destruição dos perfis de alteração dos granitos, ou como simples fiadas, mais ou menos contínuas, desses blocos. Os principais critérios que serviram de base para a identi- 




Foto 1 - Depósito de moreia, ligeiramente deslocada, na vertente norte do entalhe da Corga das Quebradas.

Photo 1 - Moraine deposit (Corga das Quebradas).

crista ou em arco, em posição de interflúvio ou atravessando os vales, não podendo por isso confundir-se com os depósitos fluviais; 2) a inclusão de blocos de grande dimensão afastados das vertentes declivosas, logo não deslocados por simples gravidade; 3) o carácter arredondado desses blocos, ao contrário do achatamento típico dos depósitos crioclásticos.

Algumas novas moreias por nós identificadas, por vezes reduzidas a simples fiadas de blocos, foram fundamentais para a delimitação da calote de planalto e para a determinação da espessura atingida pelo gelo, como por exemplo a moreia de Penedo Redondo, que domina o vale do Couce, e a do Cabeço de Obecedo, supensa sobre o vale do Homem. Pelo contrário, algumas moreias referidas por CoudÉ-GAUSSEN $(1979,1981)$, nomeadamente no sector de Prados da Messe - Curral da Rocalva, não puderam ser por nós confirmadas, devido à conformidade da disposição dos blocos com o sistema de fracturação do substrato. Mas em vários casos, na ausência de cortes, que é a situação mais frequente, pode ficar-se na dúvida se se trata de acumulação morénica ou de simples alteração superficial dos granitos. O mimetismo é particularmente forte no caso dos granitos vermelhos. 


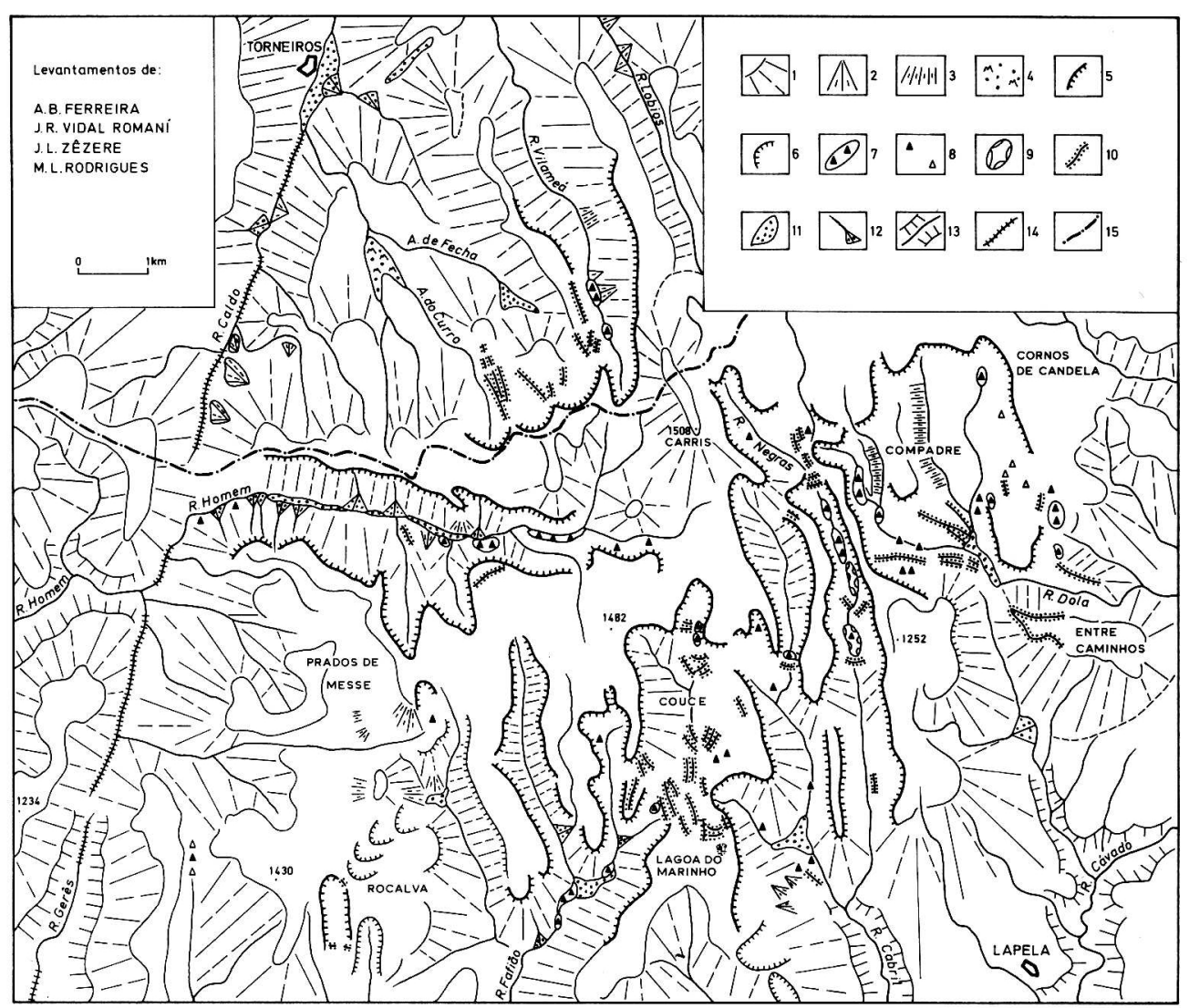

Fig. 1 - Esboço geomorfológico da glaciação plistocénica da Serra do Gerês.

1 - Vertente regularizada; 2 - acumulação crioclástica de vertente, em cone; 3 - acumulação crioclástica de vertente, em talude; 4 - escoada de blocos; 5 - rebordo de circo ou de vale glaciário; 6 -idem, provável; 7 - till subglaciário; 8 - afloramento isolado de till subglaciário, certo (a) e provável (b); 9 - till supraglaciário; 10-moreia; 11 -acumulação grosseira de fundo de vale, provavelmente fluvioglaciária; 12 - acumulação grosseira, em cone; 13 - garganta; 14 - vale de fractura do Gerês-Caldo; 15 - fronteira galaico-portuguesa.

Fig. 1 -Geomorphological sketch map of the Serra do Gerês pleistocene glaciation.

1 -Richter denudation slope; 2 - cone of cryoclastic debris; 3 -talus of cryoclastic debris; 4-block flow; 5 -cirque or glacial valley; 6-the same, probable; 7-subglacial till; 8-isolate outcrop of subglacial till, certain (a) and probable (b); 9-supraglacial till; 10-moraine; 11-coarse valley-floor accumulation, probably fluvioglacial; 12 -fluvial or fluvio-glacial cone; 13-gorge; 14-fault-line valley; 15 - Spanish border. 


\section{Os sedimentos glaciários (till)}

\subsection{Os diferentes tipos de till}

De importância fundamental para a determinação dos limites da glaciação e para a atribuição da origem glaciária a várias formas de relevo pouco nítidas, foi a identificação de sedimentos glaciários, nomeadamente dos tills subglaciários. Estes ocorrem geralmente em afloramentos descontínuos e pouco espessos, raras vezes ultrapassando a espessura de um metro. Em observação de campo esses depósitos apresentam uma composição semelhante à das areias graníticas, mas incorporam calhaus, normalmente subangulosos, e apresentam geralmente forte compacção, por vezes foliação nos materiais mais finos, e em vários casos pode observar-se injecção ao longo das diaclases do antigo leito glaciário.

A análise sedimentológica de campo foi apoiada pelo estudo micromorfológico (VAN DER MEER, 1987) de várias amostras e pela morfoscopia de grãos de quartzo ao microscópio electrónico (PertTunen e Hirvas, 1982). Com base em Dreimanis (1988), foram estabelecidos os seguintes tipos de till (VIDaL RoMANí et al., 1990 b):

- till de acreção ou de alojamento (lodgement till);

- till de fusão subglaciária (subglacial melt-out till);

- till de deformação (deformation till);

- till supraglaciário ou de ablação (supraglacial ou ablation till).

\subsection{Descrição de alguns cortes mais representativos}

a) Till de acreção, na cabeceira do vale de Vilameá. Pode observar-se, de forma descontínua, ao longo do caminho para a mina de As Sombras, a seguir ao desvio do estradão florestal da Portela do Homem. O depósito atinge a espessura média de um metro e assenta em substrato granítico polido e estriado. Apresenta uma matriz areno-pelítica, compactada, com foliação mais clara na base do depósito. A maioria dos calhaus incluídos no depósito são subangulosos e por vezes com faces triangulares, o que constitui uma particularidade desses diamicton (fot. 2).

Em observação microscópica, a matriz apresenta um fácies brechóide-milonítico, de grãos de quartzo e de feldspato geralmente angulosos, com textura granossuportada, excepto quando a matriz fina se torna mais abundante. Em algumas amostras foi observada a estrutura skelsepic, própria dos tills de acreção. Por sua vez, a morfologia dos grãos de quartzo ao microscópio electrónico de varrimento mostra as marcas típicas de estriamento e fracturas concoidais em escadaria (fot. 3 ), que se associam aos ambientes sedimentares de deformação (PertTunEn e HiRvas, 1982). 
b) A sequência sedimentar da Ribeira das Negras. Os melhores cortes encontram-se no terço superior do vale, onde é possível observar a sobreposição de três tipos de sedimentos: um till de acreção na base; segue-se um till de fusão subglaciária; este, por sua vez, é coberto por um till supraglaciário (fig. 2).

O till de acreção apresenta matriz areno-pelítica, muito compactada, com foliação marcada no material fino, adaptando-se aos contornos dos clastos. Por vezes a textura torna-se clastossuportada, sendo neste caso a foliação pouco nítida, mas os clastos estão orientados, revelando o sentido do fluxo glaciário. Ao microscópio, a matriz apresenta o típico aspecto brechóide-milonítico (fot. 4), com estrutura granossuportada, com fracção silto-argilosa que prenche os espaços. Observa-se por vezes uma estrutura skelsepic, com bandas de filossilicatos deformados. Os grãos de quartzo apresentam ao microscópio electrónico de varrimento a já citada morfologia angulosa, com fracturas concoidais em escadaria, características relacionadas com os ambientes subglaciários de deformação.

A parte superior do depósito apresenta pequenas lentículas e laminações de areias, indicando circulação de água em meio subglaciário. Este depósito é interpretado como sendo um till de fusão subglaciária. Por cima deste till, encontra-se ainda uma acumulação de blocos, que interpretamos como sèndo till supraglaciário (fig. 2).

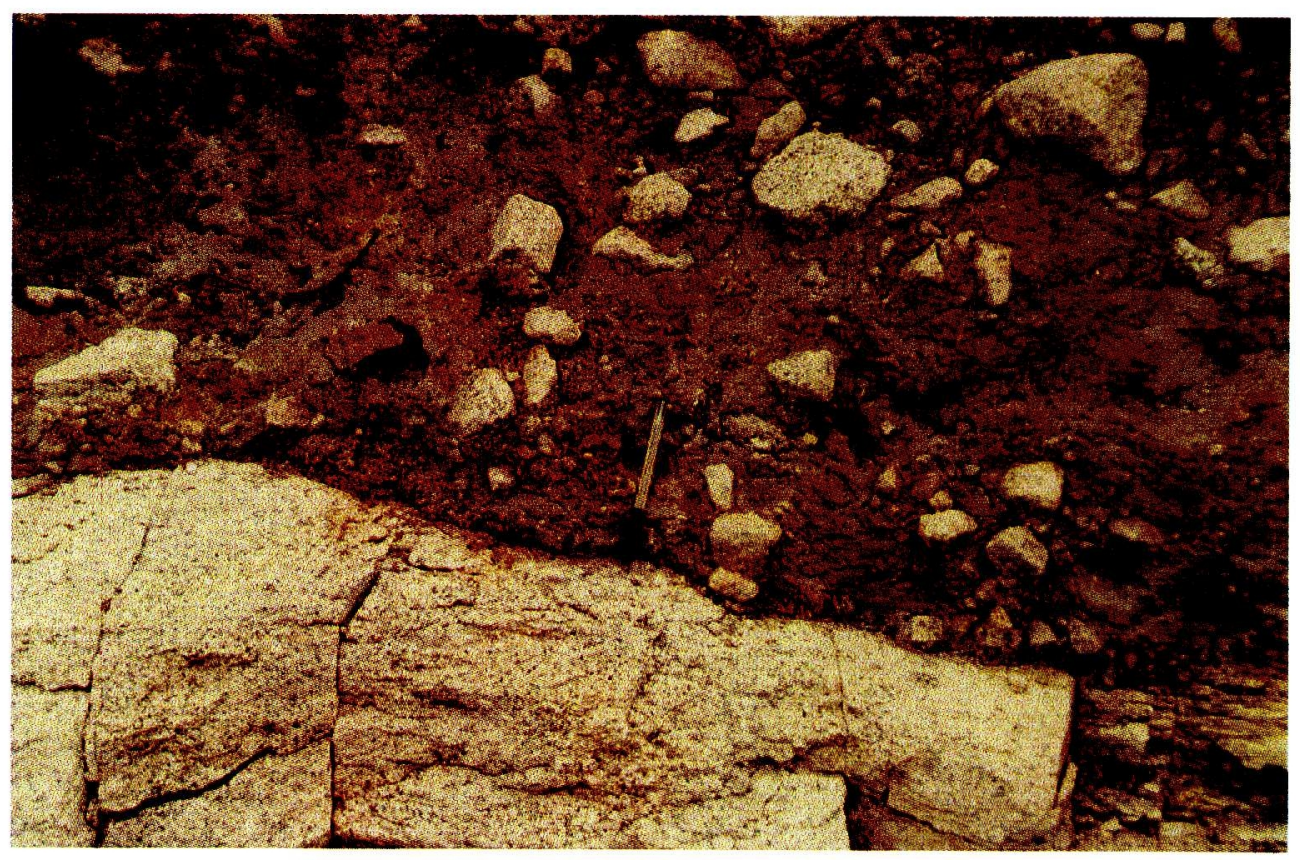

Foto 2 - Till de acreção ou de alojamento, no vale de Vilameá, a sul da mina de As Sombras.

Photo 2 - Lodgement till, in the Vilameá upper valley. 


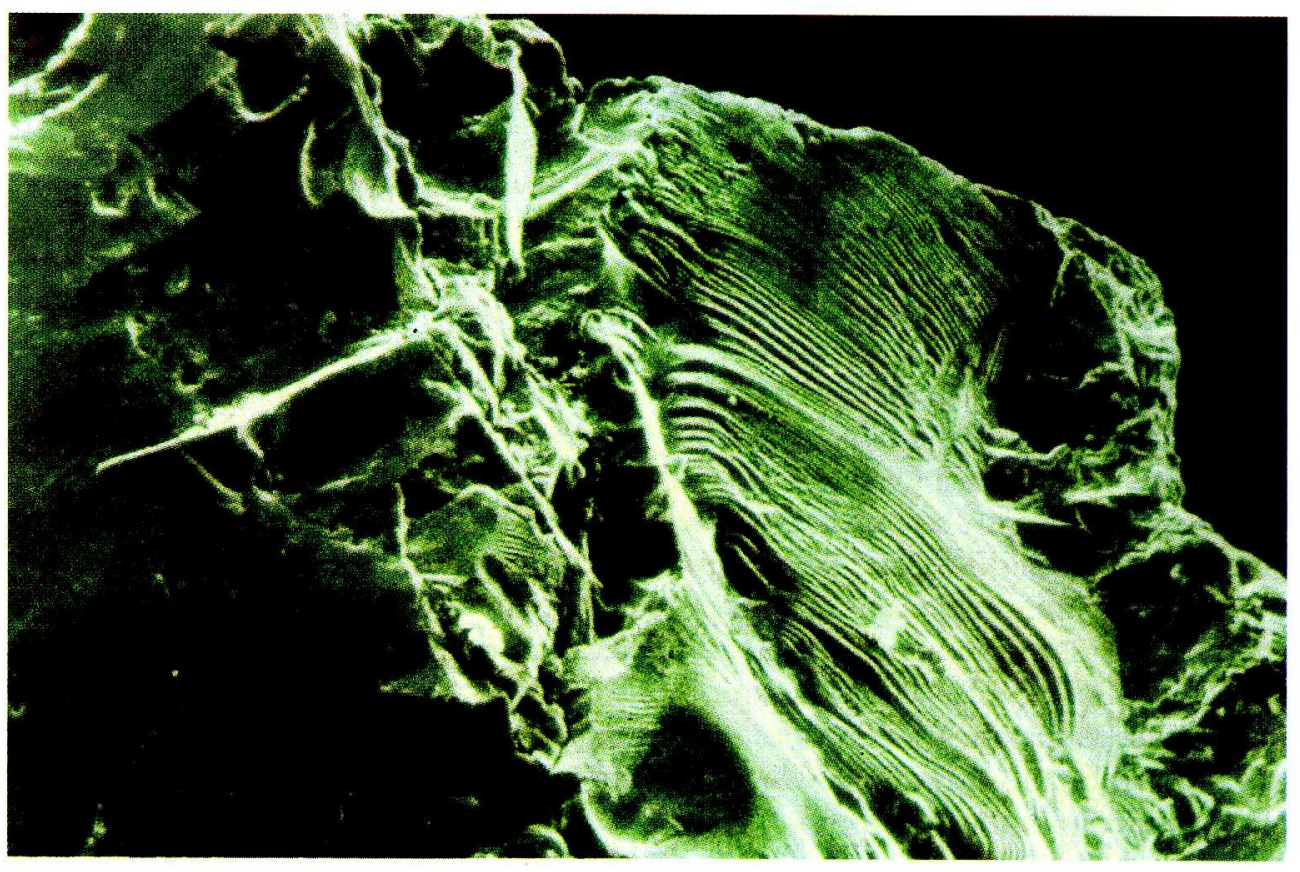

Foto 3 - Aspecto de grão de quartzo de till de acreção do vale do Homem, observado ao microscópio electrónico Photo 3 - Quartz grain of a lodgement till from the Homem valley (image obtained by scanning electron microscope).

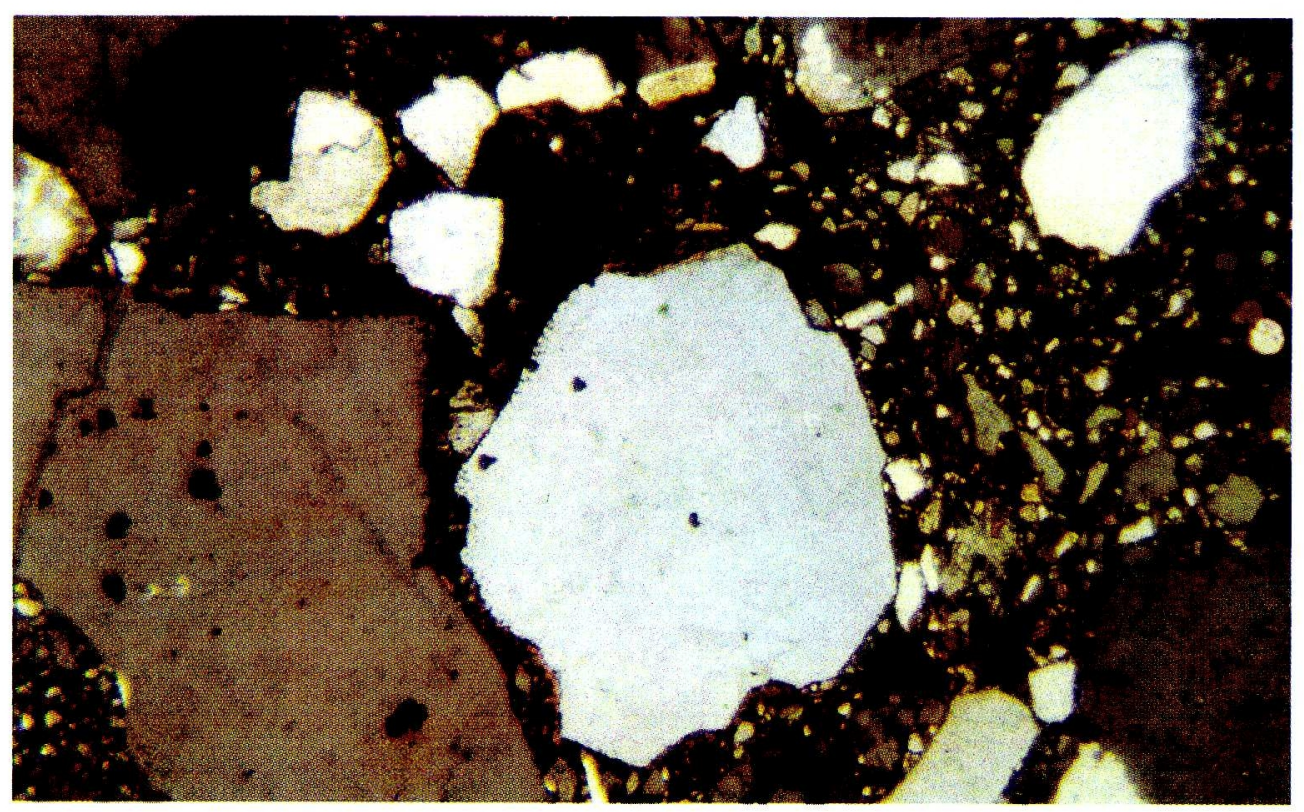

Foto 4 - Aspecto da textura de till de acreção do vale da Ribeira das Negras, observado ao microscópio electrónico. Photo 4 - Texture of a lodgement till from Ribeira das Negras valley (image obtained by scanning electron microscope). 


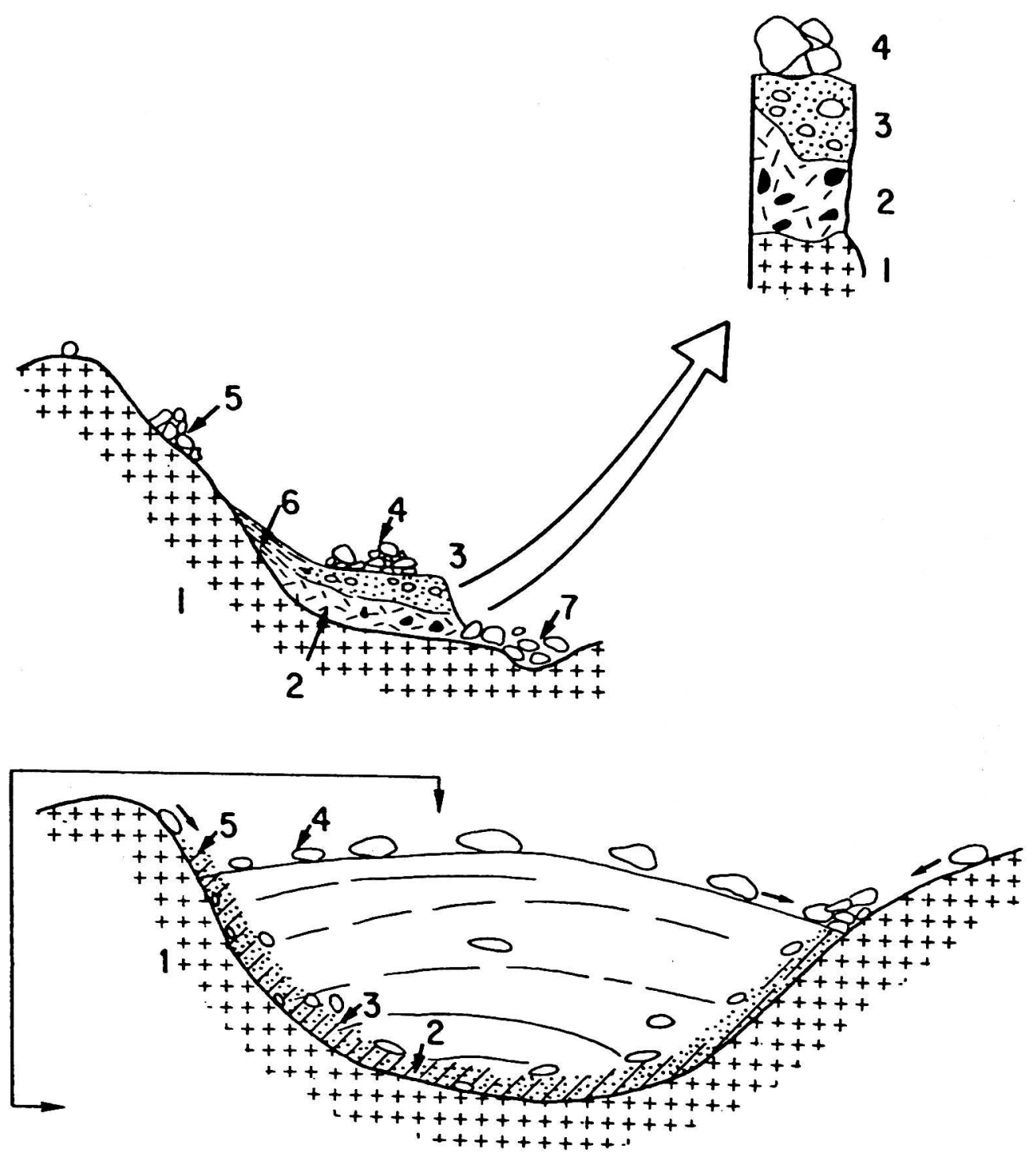

Fig. 2. - Modelo sedimentar do glaciar da Rib. a das Negras (Vidal Romaní et al., 1990 b)

1 - Substrato granítico; 2 - till de acreção; 3 -till de fusão subglaciária; 4 -blocos supraglaciários; 5 - moreia lateral; 6 - depósitos de vertente; 7 - acumulação fluviotorrencial.

Fig. 2. - Depositional pattern of Rib. ${ }^{a}$ das Negras glacier (Vidal Romaní et al., 1990 b).

1 -Granitic substratum; 2 - lodgement till; 3 -subglacial melt-out till; 4 -supraglacial blocks; 5 -lateral moraine; 6 -slope deposits; 7 - fluvio-torrential deposits.

c) O complexo sedimentar do Fafião. No caminho que dá acesso ao Porto da Lage, para sul do vale de Corgo de Valongo, encontra-se, do lado ocidental, um afloramento contínuo de depósitos numa extensão de 350 metros, em que se podem distinguir três unidades sobrepostas (fig. 3). 

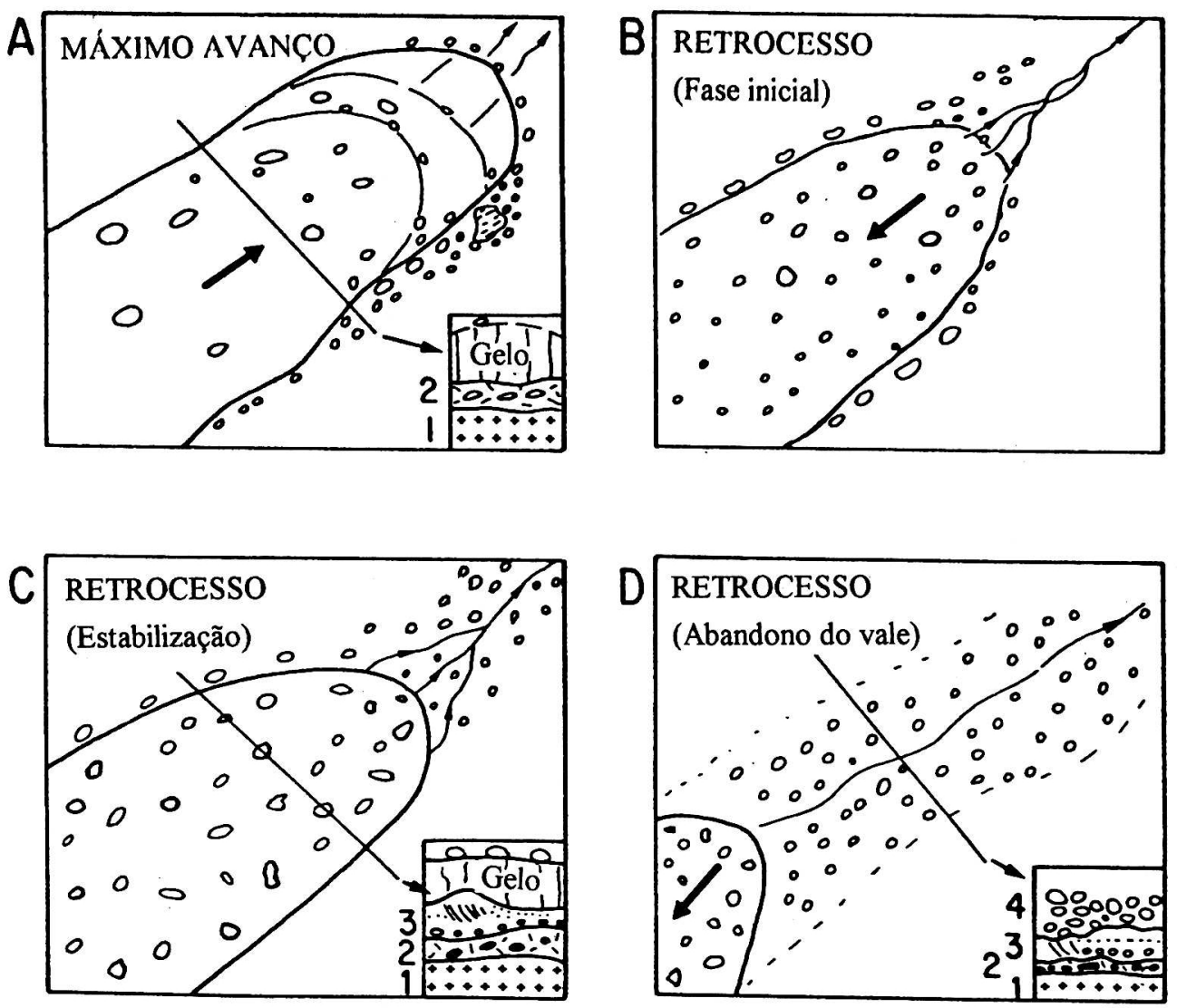

Fig. 3. - Evolução dinâmica e sedimentar da margem glaciária no vale do Fafião (Vidal Romaní et al., 1990 b). 1 - Substrato granítico; 2 - till de acreção; 3 -depósito fluvioglaciário; 4 - till supraglaciário.

Fig. 3. - Dynamics and sedimentary evolution of the glacial margin in Fafião valley (Vidal Romaní et al., 1990 b). 1-Granitic substratum; 2 -lodgement till; 3 -fluvioglacial deposit; 4-supraglacial till.

A unidade inferior é um diamicton com predomínio de uma matriz silto-arenosa, compactada, com a espessura máxima de meio metro. Ao microscópio, a matriz apresenta aspecto brechóide-milonítico, estrutura granossuportada com matriz argilosa intersticial, por vezes com estrutura skelsepic. Os grãos de quartzo apresentam ao microscópio electrónico as características já citadas dos ambientes de deformação. Trata-se de um till de acreção.

A unidade intermédia é constituída essencialmente por areias grosseiras a finas, com laminação entrecruzada e com geometria de canais de base erosiva. Intercalados nas areias, encontram-se com frequência calhaus, que podem apresentar marcas de erosão glaciária. Devido ao baixo grau de compacção deste material, não foram feitas lâminas delgadas para observação ao micros- 
cópio. Este depósito parece ter origem numa torrente subglaciária, o que é sublinhado por uma deformação das estruturas sedimentares.

A unidade superior assenta, por contacto erosivo, nesse depósito arenoso. É um diamicton clastossuportado, onde existem grandes blocos, com espaços prenchidos por calhaus e areias. A sua compacção é inferior à da unidade basal. Também aqui, devido ao baixo grau de compacção, não foram feitas lâminas delgadas. É interpretado como um till de ablação glaciária.

Em termos de dinâmica glaciária, a unidade inferior deverá corresponder a uma fase de avanço máximo da língua glaciária, a unidade intermédia assinalaria um início de retrocesso glaciário, e a unidade superior denunciaria um claro retrocesso da língua glaciária, a qual, nesta fase, se situaria a montante deste sector do vale (fig. 3 ).

\section{Vertentes regularizadas e depósitos periglaciários}

Existem na Serra do Gerês vestígios inconfundíveis da morfogénese periglaciária, mas as manifestações são relativamente monótonas, pouco diferenciadas. Os vestígios mais comuns da acção do gelo no solo são constituídos por vertentes regularizadas, de perfil rectilíneo, apresentando ou não cornija rochosa superior, e cobertas, de maneira mais ou menos descontínua, na metade ou no terço inferior, por depósitos crioclásticos grosseiros, com matriz na maior parte das vezes pouco abundante. Nas áreas sujeitas à glaciação podem distinguir-se três gerações desses depósitos de vertentes regularizadas.

Os depósitos de primeira geração são essencialmente constituídos por blocos morénicos, os quais terão sido transportados ao longo das vertentes logo a seguir à fusão dos glaciares de vale (fot. 1). Estes materiais assentam sobre os till subglaciários, quando é possível observá-los no mesmo corte.

Uma segunda geração de depósitos de vertente das áreas glaciadas, mas que deve ser contemporânea da glaciação nas áreas não afectadas pelos glaciares, é constituída pelos crioclastos mais típicos, com blocos e calhaus angulosos e achatados, dispostos paralelamente à vertente, apresentando por vezes uma estrutura que faz lembrar as arènes litées, descritas no Maciço Central francês (GODARD, 1972; VALADAS, 1984), mas com intercalações de calhaus.

Uma terceira geração de acumulações de vertente é constituída por material menos claramente crioclástico, em que se misturam calhaus e blocos achatados com outros clastos de forma atípica.

Há ainda a considerar acumulações de vertente mais recentes, que devem ser pós-glaciárias, provavelmente holocénicas. Estes depósitos são constituídos por calhaus de morfologia diversa e blocos arredondados, envoltos numa matriz negra, ao contrário dos depósitos anteriores, que apresentam matriz clara, amarelada. Essa matriz negra parece resultar da destruição de solos de tipo ranker. 


\section{Cones e acumulações grosseiras de fundo de vale}

Além dos depósitos citados, existem na Serra do Gerês acumulações de material muito grosseiro, incluindo blocos que podem atingir mais de um metro cúbico, e que se apresentam sob duas formas: cones, e acumulações grosseiras de fundo de vale, apresentando geralmente forte declive.

É possível que grande parte deste material grosseiro tenha origem na destruição de antigas moreias, tendo sido deslocado por acção conjunta da gravidade e do escoamento fluvioglaciário. Algumas dessas acumulações grosseiras puderam ser interpretadas como till supraglaciário, quando outros depósitos glaciários permitiram reconstituir a dinâmica da glaciação. Isso acontece por exemplo no vale da Ribeira das Negras e, no Alto Fafião, no sector de Portas do Abelheiro. Noutros casos, as acumulações grosseiras correspondem à coalescência de taludes de acumulação periglaciária, havendo exemplos muito claros na área de Compadre, ao longo do Corgo de Lamelas e do Corgo de Lamas do Compadre.

No que se refere aos cones, a sua origem em depósitos morénicos é sugerida pela ausência de bacia de recepção ou por uma bacia de recepção mal definida, como acontece frequentemente ao longo do vale do Homem. No entanto, por falta de provas concludentes, em vários casos ficar-se-á sem saber ao certo em que medida as acumulações grosseiras estarão relacionadas com a fusão glaciária, com a dinâmica crionival ou com a forte torrencialidade pós-glaciária.

\section{EXTENSÃO E DINÂMICA DA GLACIAÇÃO}

\section{As associações de formas e depósitos}

Para a caracterização da glaciação do Gerês, foi da maior importância o estudo das relações entre as formas e depósitos e da sua organização espacial, o que só foi possível mediante o levantamento cartográfico sector por sector. Serão evocados aqui os principais sítios da morfogénese glaciária do Gerês. Uma descrição e discussão mais pormenorizadas, assim como uma representação cartográfica mais completa, encontra-se em FerReIra et al., 1999.

\subsection{O vale do Couce}

O vale do Couce é uma forma ampla, de vertentes abruptas, com um fundo à altitude de $1150 \mathrm{~m}$, suspenso cerca de $350 \mathrm{~m}$ sobre o Rio Cabril. É talvez aqui que se encontra a mais expressiva paisagem glaciária de todo o Gerês, facto que não passou despercebido a GiRÃo (1958). Mesmo MARTínez de Pisón e ARENILlas PARRa (1984), que praticamente negam a existência de glaciação na Serra do Gerês, admitem que, na área do Couce, «existe um limitado relevo 
glaciário que nasce no circo do Concelinho e morre em seguida sobre a garganta de Pena Calva» (ob. cit., p. 169). Não deixa de ser curioso o facto de Schmidt-Thомé $(1973,1978)$, que defende a existência de uma importante glaciação no vale do Homem, não fazer referência ao vale do Couce, que the fica muito próximo. Pelo contrário, Coudé-Gaussen (1981, p. 157-161) descreve nesta área todo um cortejo de formas erosivas como circos, ferrolhos glaciários, rochas polidas e em «dorso de baleia», além de acumulações morénicas em toalha e em arco.

O circo de Cocões de Concelinho é de facto a forma erosiva glaciária mais nítida da Serra do Gerês. As moreias, como sempre acontece nesta montanha, são pouco espessas ou mesmo encontram-se reduzidas a filas de blocos. O estudo paciente de campo permitiu reconhecer uma certa organização espacial nesses depósitos, onde se individualizam cinco ou seis posições relacionadas com fases sucessivas de recessão glaciária. Mais importante do que isso foi a descoberta de moreias altas, do lado ocidental do vale, a do Penedo Redondo e a da Meda do Borrageiro, que permitem calcular uma espessura de gelo da ordem dos 150 m, no vale do Couce, no máximo da glaciação. Espessura semelhante de gelo era também admitida por Coudé-GAUSSEN (1981), mas não foi convenientemente demonstrada. Refira-se também a descoberta de vários afloramentos de till subglaciário, sobretudo à saída do circo do Curral da Maceira, a $1250 \mathrm{~m}$ de altitude, e do lado oriental do vale, entre 1150 e $1125 \mathrm{~m}$ de altitude (fig. 1).

\subsection{O vale da Ribeira das Negras}

O estudo de campo revelou a existência, neste vale, de uma das mais claras e ricas associações de till que existem na Serra do Gerês, em afloramentos relativamente extensos, sobretudo no terço superior do vale. A associação consiste, como se disse, na seguinte sequência, de baixo para cima (fig. 2): till de acreção, till de fusão subglaciária e till supraglaciário. Coudé-Gaussen (1981) considera também que este vale terá sido percorrido por uma língua glaciária, até cerca de 1000 de altitude, mas aduz poucas provas: o belo circo glaciário da Ribeira das Negras é descrito como «uma cabeceira de valeiro tendo funcionado como circo glaciário» (ob. cit., fig. 54, p. 170) e refere-se a existência de um retalho de «moreia em toalha», perto do final da língua glaciária deduzida.

\subsection{O alto vale do rio Homem}

Como se referiu, segundo Schmidt-Thomé $(1973,1978)$, o glaciar do vale do Homem teria atingido, a jusante, a altitude de $600 \mathrm{~m}$, e uma espessura, a montante, de $500 \mathrm{~m}$. Pelo contrário, Coudé-Gaussen (1981) acha que apenas seria possível provar a existência de uma língua glaciária no vale afluente de Água da Pala, a qual teria atingido a altitude de 900 m (ob. cit., p. 182-183), 
enquanto no vale principal «a glaciação, se ocorreu, parou bem mais alto e não ultrapassou, certamente, a curva dos $1100 \mathrm{m»} \mathrm{(ob.} \mathrm{cit.,} \mathrm{p.} \mathrm{184).}$

As nossas observações de campo permitiram identificar afloramentos de till subglaciário no vale do Homem, desde o encaixe do rio a cerca de $1300 \mathrm{~m}$ de altitude, até à Ponte do Rio Homem (ou Ponte de S. Miguel), à altitude de $725 \mathrm{~m}$. Os mais extensos afloramentos de till subglaciário encontram-se, no entanto, no caminho para os Carris, entre os vales das ribeiras de Madorno e do Cagarouço (fig. 4). A descoberta da moreia do Cabeço de Obecedo, dominando a íngreme vertente do vale do Homem, entre aquelas duas ribeiras, permite avaliar uma espessura de $300 \mathrm{~m}$ para a língua glaciária neste sector.

\subsection{A vertente galega}

Segundo Schмidт-Tномé (1978, p. 233), a língua glaciária do vale do Homem teria difluído para norte, passando a portela do Homem, originando o glaciar do vale do Rio Caldo, o qual teria deixado moreias frontais às altitudes de 650,600 e $500 \mathrm{~m}$. Um outro glaciar, descendo do alto do Gerês, com 6 km de comprimento, terminaria a sul de Torneiros, onde se encontraria a moreia mais baixa de toda a região, a $450 \mathrm{~m}$ de altitude (ob. cit., p. 228). No entanto, de acordo com o mesmo autor, os melhores vestígios da glaciação da vertente galega encontrar-se-iam no alto vale do Rio Vilameá, onde se observariam moreias laterais entre 1300 e 1100 de altitude, numa extensão de $2 \mathrm{~km}$ (ob. cit., p. 228).

Não confirmamos a glaciação do vale do Caldo, onde apenas encontrámos escoadas de blocos de origem crionival e acumulações torrenciais, provavelmente fluvioglaciárias. No entanto é indiscutível a existência de glaciação na vertente galega, embora de extensão limitada. A associação mais clara dos vestígios dessa glaciação encontra-se justamente no sector montante do vale do Rio Vilameá, em que se podem observar, no caminho para a mina de As Sombras, till de acreção (fot. 2), rochas estriadas e um conjunto de moreias suspensas sobre o vale, do lado ocidental.

\subsection{O alto vale do Rio Fafião}

O alto vale do Rio Fafião é constituído por um conjunto de vales de fractura, com vertentes regularizadas, onde são frequentes os afloramentos em depósitos crioclásticos. É neste vale, entre Portas do Abelheiro e Porto da Lage, que se encontra o único complexo sedimentar glaciário terminal da Serra do Gerês e que já foi descrito no ponto III, 3.2. Coudé-Gaussen (1981, p. 178) considerou estes depósitos como um terraço de kame. Como se disse, o afloramento atinge uma extensão de $350 \mathrm{~m}$, e nele observa-se uma sobreposição de till de acreção, till de fusão subglaciária e till supraglaciário. De sublinhar também a existência, a montante deste complexo terminal, de vários afloramentos de till de acreção. 


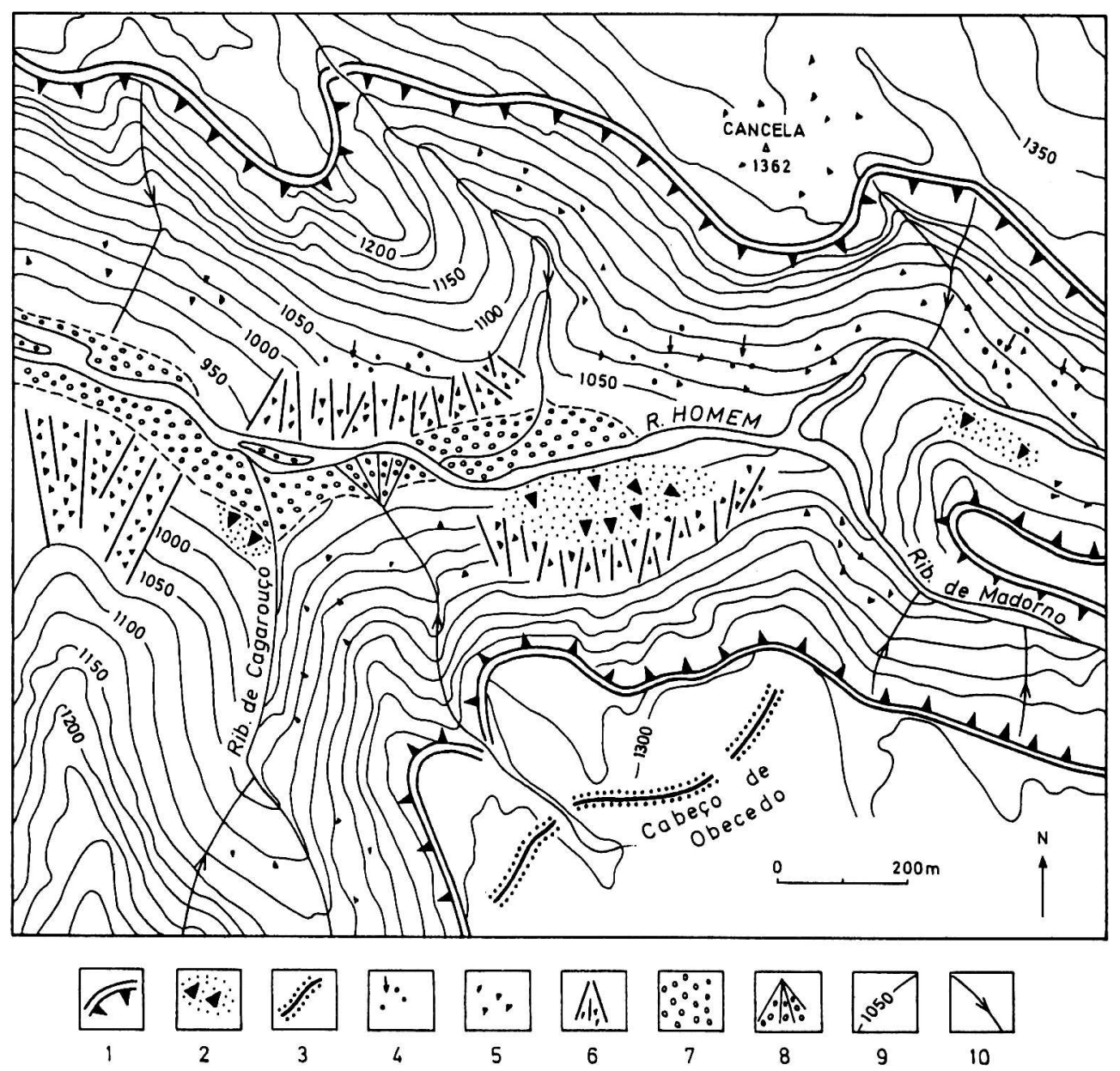

Fig. 4. - Depósitos glaciários e periglaciários do alto vale do Homem (Ferreira et al., 1992).

1 -vale glaciário; 2 -till subglaciário; 3 -alinhamento de blocos de moreia; 4-blocos de moreia desabados; 5 - cobertura esparsa de blocos das vertentes regularizadas; 6 - escoada de blocos; depósito crionival; 7 - acumulação fluvioglaciária; 8 - cone; 9 - curva de nível (equidistância de 25 m); 10 - barranco.

Fig. 4. - Glacial and periglacial deposits in the Homem upper valley (Ferreira et al., 1992).

1 - Glacial valley; 2 - subglacial till; 3 - alignment of moraine blocs; 4 -displaced moraine blocs; 5 - sparce clast covering of Richter denudation-slope; 6-talus; 7 -fluvioglacial deposits; 8 -cone; 9-countour line (countour interval, $25 \mathrm{~m}$ ); 10 -creek.

\subsection{O sector oriental (área de Compadre)}

De acordo com CoudÉ-Gaussen (1981), na área de Compadre «os vestígios da glaciação são mais discretos do que nas duas outras grandes depressões do Gerês Central» (ob. cit., p. 169), sendo uma dessas depressões o vale do Couce e a outra a de Prados de Messe, de que falaremos no ponto seguinte. E acres- 
centa que, não fora a moreia de Compadre, o relevo poderia confundir-se com «uma topografia granítica banal». Além de um arco morénico em Compadre, a autora refere-se ainda a "moreia em toalha», que existiria ao longo dos principais valeiros que percorrem a depressão.

Do nosso ponto de vista, a área de Compadre é um dos sectores do Gerês em que os vestígios da glaciação são mais evidentes e constitui uma das áreas, juntamente com o vale do Couce, onde a acumulação de gelo foi mais importante. Toda a paisagem é marcada por vertentes rochosas nuas ou percorridas por filas de blocos. É uma das áreas em que as moreias são mais abundantes, situação apenas comparável à do vale do Couce. Mas essas moreias são por vezes pouco nítidas, difíceis de individualizar, e só a descoberta de vários afloramentos de till subglaciário permitiu um diagnóstico relativamente seguro. Os afloramentos de till encontram-se sobretudo ao longo do vale do Ribeiro da Biduíça e também junto à vertente Ocidental dos Cornos de Candela e no Alto de Bezerral (fig. 1). Estes afloramentos de depósitos subglaciários permitem reconstituir uma acumulação de gelo da ordem dos $150 \mathrm{~m}$, no máximo da glaciação, ou seja, uma espessura semelhante, como se disse, à do glaciar do Couce.

\subsection{O sector ocidental (Prados de Messe-Curral da Rocalva)}

Segundo Coudé-Gaussen (1981, p. 167-169) existiria um «complexo glaciário» na depressão de Prados de Messe, que permitiria deduzir uma acumulação de gelo com $150 \mathrm{~m}$ de espessura. Os vestígios seriam a existência de moreias em «bourrelet», a sul e a norte da depressão, moreias em «caudas de cometa», no sopé setentrional da penha de Albas (1392 m), ou, ainda, moreias em toalha, no fundo da depressão.

Não nos foi possível confirmar a existência dessas moreias em «bourrelet», que nos pareceram formas de alteração do substrato, embora, na falta de cortes, possa subsistir alguma dúvida. O depósito da penha de Albas pareceu-nos ligado à dinâmica periglaciária, e, no fundo da depressão, não encontrámos nenhum afloramento de till. No entanto, confirmamos os terraços de obturação glaciária do pequeno afluente da Ribeira do Porto das Vacas, onde encontrámos um afloramento de till subglaciário a $1230 \mathrm{~m}$ de altitude. Os vestígios mais claros de toda a área parecem-nos ser as pequenas moreias do Curral da Rocalva, que permitem deduzir uma acumulação de 50 metros de gelo. Admite-se a hipótese de que a acumulação de gelo nessa área tenha sido mais importante, mas não encontrámos provas suficientes, nomeadamente afloramentos de till subglaciário, os quais são, em todo este sector ocidental do Gerês, muito dispersos e mal definidos. 


\section{Os limites da glaciação}

\subsection{O limite ocidental}

Como se acaba de referir, os vestígios da glaciação do Gerês não são muito abundantes nem muito claros no lado ocidental. $\mathrm{O}$ sector melhor caracterizado é o vale do Homem, onde o till subglaciário da Ponte do Rio Homem (Ponte de S. Miguel) permite concluir que o glaciar atingiu a altitude de $725 \mathrm{~m}$. No planalto, é difícil dizer se o glaciar ultrapassou, para oeste, o Curral da Rocalva, uma vez que os afloramentos de till do colo da Freza, entre 1190 e 1170 m de altitude, são pouco claros. Ainda mais para oeste, na Serra Amarela, existem duas moreias, entre 1165 e $1080 \mathrm{~m}$ de altitude. Não nos parece que essas moreias marquem uma extensão para oeste dos glaciares da Serra do Gerês, constituindo antes uma réplica isolada da glaciação.

\subsection{O limite oriental}

Os limites orientais da glaciação são, pelo contrário, bastante claros. O glaciar preenchia, no máximo da glaciação, a depressão de Compadre, mas não ultrapassava, para oriente, os relevos de Cornos de Candela. O limite da glaciação é muito brusco no interflúvio de Sesta do Carneiro/Entre Caminhos, sem qualquer obstáculo orográfico que o justifique. Este limite, situado a $1010 \mathrm{~m}$ de altitude, é sublinhado por moreias e um afloramento de till subglaciário, na vizinhança imediata de uma morfologia típica de alteração granítica. A moreia suspensa sobre o vale do Ribeiro Dola desce bastante mais baixo, até à altitude de $925 \mathrm{~m}$.

\subsection{O limite setentrional}

Na vertente galega, o till mais baixo que foi possível identificar fica a 1050 m de altitude, no vale do Rio Vilameá, e a língua glaciária deveria descer um pouco mais. Por sua vez, as pequenas cristas morénicas situadas entre este vale e o do Arroyo da Fecha ficam entre 1250 e $1110 \mathrm{~m}$ de altitude, enquanto entre este vale e o do Arroyo do Curro, elas ficam entre 1320 e $1120 \mathrm{~m}$.

\subsection{O limite meridional}

Do lado meridional, o mais seguro limite da glaciação é dado pelo complexo sedimentar terminal do Fafião, o qual atinge a altitude de $860 \mathrm{~m}$, que deveria ser também a altitude mínima alcançada pela língua glaciária. No vale da Ribeira das Negras, os afloramentos de till não descem abaixo de $1020 \mathrm{~m}$ de altitude, mas encontra-se uma pequena acumulação de blocos mais a jusante, à altitude de $925 \mathrm{~m}$, que pode ser interpretada como moreia lateral. No esporão da Corga das Quebradas, no alto vale do Cabril, encontrou-se uma pequena moreia 
entre 850 e 775 m de altitude, a mais baixa moreia da Serra do Gerês. Embora ela pareça estar ligeiramente deslocada pela dinâmica periglaciária, é possível dizer-se que uma língua glaciária, oriunda do entalhe da Corga de Pena Calva e, provavelmente, também da Corga de Sabroso, terá atingido, no vale do Cabril, uma altitude pouco superior a $700 \mathrm{~m}$.

\section{As fases da glaciação}

\subsection{Fase pleniglaciária: calote e línguas glaciárias}

No máximo da glaciação (fase pleniglaciária), uma cúpula de gelo ocuparia as terras altas do Centro-Leste da Serra do Gerês, de onde divergiam línguas pelos principais vales periféricos. As áreas de acumulação da neve não eram os circos, como é típico das montanhas alpinas, mas uma superfície planáltica que pouco ultrapassaria o limite das neves perpétuas. Os vestígios conservados mostram que a metade oriental da montanha, certamente por ser a mais abrigada dos ventos dominantes, permitindo uma maior acumulação de neve, conheceu uma glaciação bem mais importante que a metade ocidental.

Não se pode delimitar com segurança a extensão máxima da calote glaciária. No entanto, a moreia do Curral de Obecedo, suspensa sobre o vale do Homem, e as moreias da Meda do Borrageiro e do Penedo Redondo, na vertente ocidental do vale do Couce, podem considerar-se limites mínimos, do lado ocidental e do lado meridional. Por sua vez, o relevo de Cornos de Candela e as moreias do interflúvio de Sesta do Carneiro/Entre Caminhos, constituem limites bastante seguros, do lado oriental. Do lado norte, a calote glaciária deveria ter como limite aproximado a fronteira galaico-portuguesa, tendo alimentado por transfluência as línguas glaciárias da vertente galega.

A espessura máxima atingida pela calote glaciária, tanto no vale de Couce como na depressão de Compadre, parece ter sido da ordem dos $150 \mathrm{~m}$. Mas, no sector montante de algumas línguas de vale, a espessura do gelo pode ter sido bastante superior. No caso do glaciar do Homem, essa espessura atingiria cerca de $300 \mathrm{~m}$.

\subsection{Fase de deglaciação: predomínio dos glaciares de vale}

$\mathrm{Na}$ fase de deglaciação, à diminuição da calote de planalto corresponderia uma melhor individualização dos glaciares de vale. Com base nos afloramentos de till subglaciário e nas moreias que se conservaram até hoje, pode ter-se uma ideia da extensão máxima dos vales glaciários (quadro I). Tenha-se em atenção, no entanto, que o comprimento das línguas glaciárias era inferior ao dos vales, tanto na fase pleniglaciária como na fase de deglaciação. Na fase pleniglaciária, a parte montante dos vales estava coberta pela calote, ao passo que na fase de deglaciação as línguas prolongavam-se menos para jusante. 
QUADRO I

Características dos principais vales glaciários da Serra do Gerês.

TABLE I

Characteristics of the main glacial valleys of Serra do Gerês (length and aspect of the valleys; nature and altitude of the highest and lowest glacial deposits)

\begin{tabular}{|c|c|c|c|c|c|c|}
\hline \multirow{2}{*}{$\begin{array}{c}\text { Vale } \\
\text { glaciário }\end{array}$} & \multirow{2}{*}{$\begin{array}{c}\text { Comprimento } \\
(\mathbf{k m})\end{array}$} & \multirow{2}{*}{$\begin{array}{l}\text { Orientação } \\
\text { geral }\end{array}$} & \multicolumn{2}{|c|}{$\begin{array}{l}\text { Vestígio sedimentar } \\
\text { mais alto }\end{array}$} & \multicolumn{2}{|c|}{$\begin{array}{l}\text { Vestígio sedimentar } \\
\text { mais baixo }\end{array}$} \\
\hline & & & natureza & altitude & natureza & altitude \\
\hline Homem & 7 & $\mathrm{~W}$ & till & 1315 & till & 725 \\
\hline Couce/Cabril & 5 & $\mathrm{~S}$ & till & 1320 & moreia & 775 \\
\hline Fafião & 4 & $\mathrm{~S}$ & till & 1210 & till & 860 \\
\hline $\begin{array}{l}\text { Lamalonga/ } \\
\text { Sabroso }\end{array}$ & $\begin{array}{c}5 \\
(6,5 ?)\end{array}$ & $S$ & till & 1210 & $\begin{array}{c}\text { till } \\
\text { (moreia?) }\end{array}$ & $\begin{array}{c}900 \\
(775 ?)\end{array}$ \\
\hline Negras & 6 & $S$ & till & 1275 & moreia & 925 \\
\hline Biduiça/Dola & 5 & $\mathrm{E}$ & till; moreia & 1260 & moreia & 925 \\
\hline Vilameã & 3 & $\mathrm{~N}$ & moreia & 1240 & till & 1050 \\
\hline
\end{tabular}

Não se pode reconstituir com segurança os avanços e recuos das línguas glaciárias na fase de recessão. No entanto, a disposição actual das moreias sugere em certos casos uma evolução bastante complexa. $\mathrm{O}$ caso mais saliente é o dos vales do Couce/Cabril, em que é possível individualizar seis a sete posições das moreias, desde a Corga das Quebradas até ao circo de Maceiras, situado a leste do circo do Concelinho. Pelo contrário, no vale do Fafião, depois da fase de máximo e das primeiras fases de retrocesso, sublinhadas pelo complexo sedimentar (fig. 3), não se pode avaliar as posições sucessivas da língua glaciária ao longo do vale, devido à ausência de moreias bem definidas. O material morénico que se encontra neste vale está geralmente deslocado, por acção da gravidade e da dinâmica periglaciária.

\subsection{Fase finiglaciária: glaciares de circo}

É provável que, depois do desaparecimento da calote e das línguas glaciárias, o gelo se tenha acantonado nas cabeceiras dos vales mais favoráveis à acumulação de neve, devido à morfologia particular, em anfiteatro, e à exposição a leste, ao abrigo dos ventos dominantes. Parece ter sido o caso dos circos de Cocões de Concelinho e das Negras, que conservam ainda hoje, sobretudo o primeiro, uma frescura surpreendente. 


\section{QUADRO PALEOGEOGRÁFICO DA GLACIAÇÃo DO GERÊS}

\section{Dissimetrias regionais do limite das neves perpétuas na Península Ibérica}

Um mapa da distribuição dos limites das neves perpétuas (l.n.p.) na Península Ibérica (fig. 5) mostra um gradiente muito acentuado no Norte e no Noroeste, em que as altitudes dos l.n.p. sobem muito rapidamente do litoral

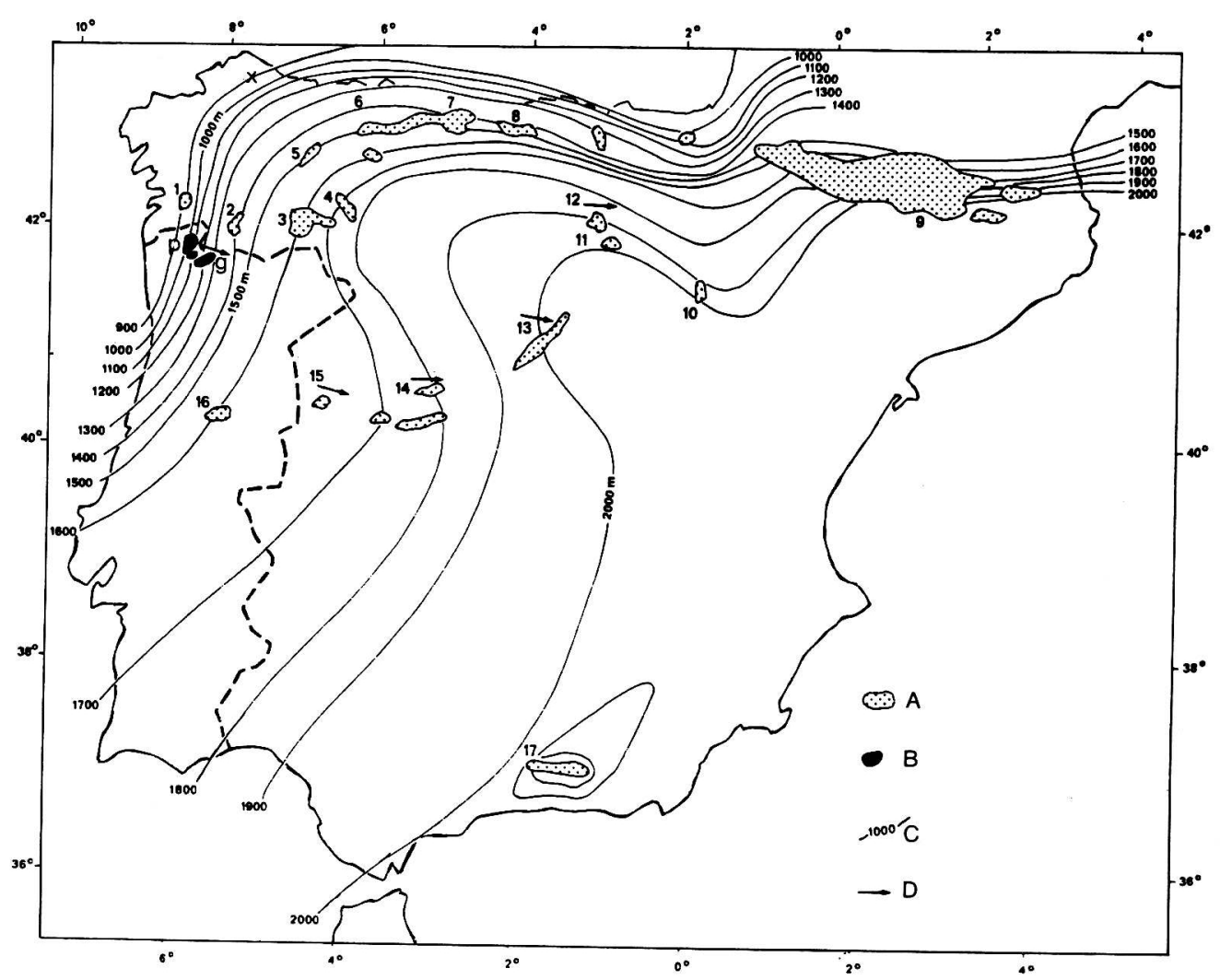

Fig. 5. - A glaciação plistocénica e o limite das neves perpétuas na Península Ibérica (Coudé-Gaussen, 1981). A - Glaciação plistocénica; B - glaciação das montanhas do Minho; C-limite das neves perpétuas, em metros; D - assimetria secundária da glaciação; 1 - Faro de Avión; 2 - Queixa; 3 - Cabrera-Segundera; 4 -Teleno; 5 -Courel; 6 -Astúrias; 7 -Picos de Europa; 8 -Reinosa; 9 -Pirenéus; 10 -Moncayo; 11 - Urbión; 12 - Demanda; 13 - Guadarrama; 14 - Gredos; 15 - Gata; 16 - Serra da Estrela; 17 - Serra Nevada. Com as letras g, p e x, assinalámos o Gerês, a Peneda e a Serra do Xistral.

Fig. 5. - The Pleistocene glaciation and the snow lines in the Iberia mountains (Coudé-Gaussen, 1981).

A- Glaciated mountains; $B$-glaciated mountains of northwestern Portugal ( $g$-Gerês; $p$-Peneda); $C$-snow lines, in metres; $D$-local dissymmetry of glaciation; 1 -Faro de Avión; 2 -Queixa; 3 -CabreraSegundera; 4-Teleno; 5 -Courel; 6-Astúrias; 7-Picos de Europa; 8-Reinosa; 9-Pirenéus; 10-Moncayo; 11-Urbión; 12 -Demanda; 13 -Guadarrama; 14-Gredos; 15 -Gata; 16-Serra da Estrela; 17-Sierra Nevada ( $x$ : localises the Serra de Xistral). 
para o interior. Embora os vestígios da glaciação em que se baseia a determinação dos l.n.p. possam ser de idades diferentes, a imagem obtida é bastante coerente, e revela a influência fundamental da humidade oceânica na origem daquele forte gradiente.

É justamente essa humidade oceânica, que favorece a precipitação nivosa, e desfavorece, pelo abaixamento da insolação, a ablação das neves e dos gelos, que explica a ocorrência de manifestações glaciárias de muito baixa altitude no Noroeste da Península Ibérica. LaUtensach (1929) propôs para a Serra da Estrela, com base na altitude das moreias laterais, um l.n.p. a $1650 \mathrm{~m}$, o que foi aceite por DAVEAU (1971). CoudÉ-GAUSSEN (1981) propôs para as serras da Peneda e do Gerês, embora com bases menos seguras, um l.n.p. da ordem de 1100-1200 m. Recorde-se que as altitudes das manifestações glaciárias destas montanhas minhotas foram consideradas demasiado baixas, e em grande parte por isso rejeitadas por alguns autores. No entanto, SchMiTz (1969) havia já proposto para a pequena montanha galega de Faro de Avión, que fica $40 \mathrm{~km}$ a norte da Serra da Peneda, um l.n.p. de 900 m, para justificar manifestações glaciárias que são, deve dizer-se, muito pouco claras. Por sua vez, PÉREz AlBerTi et al. (1993) defendem um amplo glaciarismo de baixa altitude no Noroeste peninsular, e segundo estes autores os l.n.p. teriam mesmo baixado até cerca de $800 \mathrm{~m}$, na Serra do Xistral, no extremo norte da Galiza (ob. cit., p. 458). Contudo, mais recentemente, VAlCÁrcel Diaz e Pérez Alberti (1998) são mais prudentes, referindo, para a mesma montanha, uma «linha de equilíbrio glaciário», a 900 m de altitude (ob. cit., p. 458).

\section{Dissimetrias locais da glaciação do Gerês}

LAUTENSACH (1929) chamou a atenção para a existência de uma dissimetria oeste-leste na glaciação da Serra da Estrela, com uma acumulação do gelo sobretudo do lado oriental, o que estaria relacionado, segundo o autor, com a sobrealimentação nivosa nas vertentes abrigadas dos ventos dominantes, que soprariam de oeste. GARCIA-SAINZ (1950) generalizou esta interpretação para a glaciação então conhecida na Península Ibérica. Contudo, HeRnándEZ-PACHECo (1957) considera que na Serra da Queixa-Invernadoiro, montanha galega que apresenta uma glaciação muito semelhante à da Serra do Gerês, e dista apenas $80 \mathrm{~km}$ desta, a dissimetria é antes NW-SE, pois a acumulação dos gelos verifica-se preferencialmente nas vertentes viradas a sul e a sueste. Esse facto estaria relacionado, segundo o autor, com ventos dominantes soprando de noroeste. DAVEAU (1971), embora aceitando a dissimetria W-E da glaciação na Serra da Estrela, relacionada com a precipitação nivosa, faz notar o fraco desenvolvimento dos glaciares no flanco sul, em contraste com o que se verifica nas outras vertentes da montanha; isso dever-se-ia essencialmente a uma dissimetria nortesul da insolação, perfeitamente compreensível numa montanha de afinidades mediterrâneas. Para CoUdÉ-GAUSSEN (1981), essa dissimetria da insolação não 
se verifica na Serra do Gerês, onde as condições climáticas contemporâneas da glaciação deveriam ser de tipo oceânico. A autora sublinha, mesmo, que haveria um escoamento preferencial do gelo para sul, devido às características do relevo pré-glaciário, o que «prova também a pouca eficácia da insolação sobre os gelos virados a sul» (ob. cit., p. 194).

Nas serras da Estrela, do Gerês e da Queixa-Invernadoiro (para esta última dispõe-se de alguns estudos recentes, entre os quais os de VIDAL Romaní e SANTOS, 1994, e de Vidal Romaní et al., 1995, que analisam os depósitos glaciários e as fases de deglaciação), a glaciação foi certamente muito semelhante, com uma cúpula de planalto, da qual emanavam línguas glaciárias pelos entalhes periféricos. Nestes três casos, a glaciação está fortemente influenciada pelo relevo pré-glaciário, em que as superfícies planálticas favoreceram a acumulação das neves e dos gelos, e os vales periféricos canalizaram as línguas glaciárias.

A cartografia dos vestígios glaciários da Serra do Gerês mostra claramente que a glaciação terá sido mais importante na metade oriental da montanha. Também não há dúvida que, na vertente sul, a glaciação foi bem mais importante do que na vertente galega. Ora estes contrastes não podem ser facilmente explicados apenas pelo relevo pré-glaciário. É provável que a dissimetria climática ligada à ventilação, que condiciona a acumulação da neve, logo as condições propícias à formação do gelo, não tenha sido W-E, mas antes NW-SE. Este facto poderia estar relacionado com uma inflexão do fluxo zonal oceânico para sul, à entrada da Península Ibérica, devido às condições particulares da cir-culação oceânica no Atlântico oriental, a esta latitude (PujoL, 1980;

$\begin{array}{llllllll}D & \mathrm{U} & \mathrm{P} & \mathrm{L} & \mathrm{E} & \mathrm{S} & \mathrm{S} & \mathrm{Y}\end{array}$
et al., 1981; Ruddiman e McInTyRe, 1981; Duprat, 1983; Frenzel et al., 1992).

Atendendo a essas condições da ventilação, o l.n.p. na Serra do Gerês seria mais baixo do lado sueste do que do lado noroeste, ao contrário do gradiente regional. Na vertente galega, exposta a noroeste, o l.n.p. não deveria descer abaixo de $1300 \mathrm{~m}$, se atendermos a que não existem vestígios da glaciação a oeste do Arroyo do Curro, e que, a leste, os pequenos glaciares se terão formado em condições particulares, por transfluência, no máximo da glaciação do Gerês, a partir da calote, que terminaria próximo da fronteira galaico-portuguesa. Do lado sueste, o l.n.p. deveria situar-se nos 1000 m, a leste do Bezerral e no interflúvio de Sesta do Carneiro/Entre Caminhos. No vale do Couce, o l.n.p. situar-se-ia a $1150 \mathrm{~m}$, enquanto a oeste, os vestígios conservados no Curral da Rocalva permitem supor um l.n.p. próximo de $1230 \mathrm{~m}$. Embora se trate de estimativas, esses valores mostram a dificuldade de se atribuir um valor regional ao l.n.p. da Serra do Gerês.

\section{Problemas de cronologia da glaciação}

É ideia mais ou menos generalizada que o essencial dos vestígios glaciários 
conservados na Península Ibérica se devem à Última Glaciação (Würm, da glaciação alpina), embora tenham também sido considerados alguns vestígios mais antigos. Não dispondo de nenhuma datagem absoluta da glaciação, apenas a frescura das formas glaciárias e a fraqueza dos retoques erosivos posteriores permitiram a DAVEAU (1971, p. 6) sugerir que a glaciação da Serra da Estrela pertenceria «à última fase do Würm». Na mesma ordem de ideias, CoudÉ-Gaussen (1981, p. 191) considera que a glaciação das Serras da Peneda e do Gerês terão ocorrido no «último Máximo de frio (Würm III)».

Recentemente, GRANDAL et al. (1997), ao estudarem a distribuição dos macromamíferos na Galiza, durante o Plistocénico superior, tentaram uma seriação temporal dos vestígios glaciários do Noroeste da Península, incluindo os da Serra do Gerês, tendo adoptado a cronologia estabelecida para as fases da glaciação pirenaica (BORdonAU, 1992). Esta proposta considera que o máximo da glaciação pirenaica se terá verificado entre 45.000 e 50.000 anos B.P., sendo a fase de glaciares de vale anterior a 26.000 anos B.P. Haveria assim uma certa disparidade em relação à cronologia das variações climáticas continentais durante o Plistocénico superior, e que situa o Maximo da Última Glaciação no Hemisfério Norte por volta de 20.000 - 18.000 anos B. P. De acordo com FRENZEL et al. (1992, p. 97) esta última ideia «é suportada por várias datações na América do Norte, Europa e Sibéria, indicando que o máximo avanço dos gelos continentais ocorreu depois de 22.000 anos B.P., mas antes de 17.000 anos B.P.».

A recente aplicação de uma nova técnica de datagem absoluta a uma amostragem colhida nas Serras do Gerês e da Queixa-Invernadoiro, veio revolucionar as ideias que se tinham acerca da idade da glaciação nestas montanhas, e que era tida geralmente como pertencendo apenas à Última Glaciação (Würm, da cronologia alpina). A técnica fundamenta-se na formação de novos nuclídeos sob a acção da radiação cósmica, em superfícies recém-expostas, no caso concreto em superfícies graníticas polidas pelos glaciares, e postas a descoberto pela fusão glaciária. As idades assim obtidas são normalmente idades mínimas da glaciação dos sectores da montanha a que as amostras dizem respeito, uma vez que correspondem já a uma fase de deglaciação.

A descrição da técnica utilizada, enquadramento das amostras e discussão dos resultados obtidos são sintetizados em Vidal Romaní et al., 1999. Sobre a glaciação da Serra da Queixa foram obtidas três datas: uma (amostra Q-2) sobre um bloco da moreia de Castiñeras, que é a moreia mais externa do glaciar de Cenza, correspondendo por isso à extensão máxima da glaciação, deu a idade de 126.000 anos B.P. As outras duas amostras (Q-3 e Q-4 qtz) foram colhidas em superfícies polidas cada vez mais internas, tendo-se obtido as idades muito aproximadas de 21.000 B.P. e 15.500 B.P. Na Serra do Gerês, obtiveram-se duas datas: uma (X-1), colhida no Alto da Nevosa, junto da cabeceira do vale de Vilameá, na fronteira galaico-portuguesa, forneceu a idade aproximada de 130.000 B.P, enquanto a outra (X-2), colhida entre as moreias suspensas sobre o 
vale de Vilameá, deu aproximadamente 238.000 anos B.P.

Como se vê, as diferenças entre as idades obtidas são muito grandes. Se dermos crédito a esse novo método de datagem, e apesar do número de amostras datadas ser ainda muito reduzido, o mínimo que se poderá dizer é que as manifestações glaciárias nas serras da Queixa-Invernadoiro e do Gerês parecem ser bem mais antigas do que era suposto até hoje. Na Serra da Queixa, as idades obtidas sugerem uma fase de máximo que se situaria na Penúltima Glaciação (Riss, na cronologia alpina) e fases glaciárias que se situariam no Último Pleniglaciário e no Último Tardiglaciário. No que se refere à Serra do Gerês, a idade da amostra X-1 é semelhante à de Castiñeras, e corresponderia a uma posição da calote próxima do limite máximo reconstituído pela análise geomorfológica. Como se trata de uma idade mínima, em que a calote começaria já a regredir, o máximo da glaciação pode ser bem mais antigo, o que parece, de resto, sugerir a idade obtida para a amostra X-2.

No que se refere à fase final da glaciação das montanhas do Noroeste peninsular, interessa sublinhar que nessas montanhas não parece ter havido sedimentação turfosa, junto das áreas glaciadas, antes do Dryas Antigo. De acordo com RAMIL REGO et al. (1995), a mais antiga idade obtida em turfeiras teria sido a de $13.700 \pm 300$ B.P., na Laguna de las Sanguijuelas, na Serra Segundera. Também, Vidal Romaní et al. (1995) citam a idade de $13.400 \pm 180$ B. P. para a base da turfeira da Laguna Grande (ou Laguna de Las Lamas), na Serra da Queixa. Por sua vez, VAN DER KNapP e VAN Leeuwen (1997) referem que, no antigo vale glaciário do Charco da Candeeira, na Serra da Estrela, os sedimentos lacustres anteriores à idade calibrada de 14.800 B.P. contêm muito pouca matéria orgânica. Essa quase ausência de matéria orgânica na sedimentação anterior ao Dryas Antigo seria um indicador da prevalência de condições glaciárias e periglaciárias nas áreas mais altas dessas montanhas.

Uma sondagem da Lagoa do Marinho, no planalto de Couce, a $1150 \mathrm{~m}$ de altitude, datada, na base, de $10.910 \pm 90$ B.P., revela vegetação arbórea, com predomínio do género Pinus, mas em que está presente também o Quercus. Este dado é coerente com o que se verifica noutras montanhas do Noroeste peninsular e revela a melhoria climática que anuncia o Holocénico (RAMIL REGo et al., 1995). Isso mostra também que o limite da floresta teria subido bastante em relação ao que se verificava no máximo da glaciação, se tivermos em conta, de acordo com COUDÉ-GAUSSEN (1981) que o andar das areias graníticas («étage des arènes»), que corresponderia sensivelmente ao andar da floresta, não teria ultrapassado, nas montanhas do Minho, 700-800 m de altitude.

\section{CONCLUSÃO}

A morfologia glaciária da Serra do Gerês está longe de apresentar a clareza e a frescura de que ela se reveste noutros lugares da Península Ibérica, por exemplo na Serra da Estrela. É natural, por isso, que ela tenha sido ignorada 
durante muito tempo, e até negada por visitantes apressados. A Serra do Gerês, para ser compreendida, exige habituação ao terreno, um convívio prolongado com ela e o gosto por percursos difíceis.

No estudo paciente, sector por sector, dos vestígios da glaciação, revelou-se da máxima importância a identificação dos sedimentos subglaciários. No vale do Fafião, onde esses depósitos atingem a maior espessura e a maior extensão em afloramento contínuo, foi possível definir um complexo terminal, que representa a fase de máximo e as primeiras fases de retrocesso da respectiva língua glaciária. Mas outros lugares, como o vale da Ribeira das Negras, também se revelaram muito ricos em depósitos, com till de acreção, till de ablação e till supraglaciário. A presença dos till, sobretudo os de acreção, deram muitas vezes significado a simples fiadas de blocos, que ganharam o estatuto de moreia. Algumas moreias altas, identificadas pela primeira vez, permitiram deduzir, agora com bases mais sólidas, a espessura da calote glaciária, que, na fase de máximo, terá atingido $150 \mathrm{~m}$ nos sectores do Couce e de Compadre, como, de resto, suspeitava Coudé-Gaussen. Por sua vez, a moreia do Curral de Obecedo permite afirmar que, na fase de máximo, o glaciar do vale do Homem tinha uma espessura da ordem dos $300 \mathrm{~m}$, e os afloramentos de till permitem prolongar este glaciar até à Ponte de $\mathrm{S}$. Miguel, à altitude de $725 \mathrm{~m}$. A descoberta de uma pequena moreia e de alguns afloramentos de till subglaciário a jusante da Corga da Pena Calva permitem dizer que uma língua glaciária terá atingido no vale do Cabril uma altitude próxima de $700 \mathrm{~m}$.

No total, a glaciação da vertente galega, que se terá constituído na fase de máximo por transfluência a partir da calote, é bem menos extensa do que a descrita por Schmidt-Thомé. A glaciação no vale do Rio Homem é bem mais importante do que pensava Coudé-Gaussen, e a área oriental, a leste do Couce, apresenta uma variedade e riqueza de vestígios bem superiores ao que essa autora descreveu. Pelo contrário, a área de Prados de Messe-Curral da Rocalva, no sector ocidental do Gerês, apresenta muito poucos vestígios geomorfológicos e sedimentológicos claros, e não nos foi possível confirmar no terreno, embora seja provável, a extensa glaciação dessa área, proposta por CoUdÉ-Gaussen.

\section{AGRADECIMENTOS}

O Professor Joan Manuel Vilaplana, da Universidade de Barcelona, ajudounos nas interpretações de campo e no estudo micromorfológico dos sedimentos glaciários. Carlos Monge, colaborador do Laboratorio Xeolóxico de Laxe, participou diversas vezes nos trabalhos de campo. Maite Barral, da Universidade de Santiago, auxiliou-nos no estudo morfoscópico de grãos de quartzo. O Senhor António Martinho Barreira, do Centro de Estudos Geográficos, prestou-nos grande ajuda em várias campanhas. Os Senhores Engenheiros Adolfo Augusto Morais de Macedo e José Luís da Silva Gonçalves, na sua qualidade de Directores do Parque Nacional da Peneda-Gerês, concederam-nos facilidades 
várias, nomeadamente instalação gratuita no Parque.

\section{BIBLIOGRAFIA}

BORDONAU I IBERN, J. (1992) - Els complexos glacio-lacustres relacionats amb el darrer cicle glacial als Pirineus. Geoforma Ed., Logroño, 251 p.

Carvalho, G. S.; Nunes, J. L. (1981) - A problemática dos índices glaciários quaternários nas Serras do Gerês e da Peneda. Cuad. Lab. Xeol. Laxe, 2: 289-293.

Choffaf, P. (1894) - Promenade au Gerez. Souvenirs d'un géologue. Bol Soc. Geog. Lisboa, 14. ${ }^{\mathrm{a}}$ série, 4: 385-402.

Coudé, A.; Coudé-Gaussen, G.; Daveau, S. (1983) - Nouvelles observations sur la glaciation des montagnes du Nord-Ouest du Portugal. Cuad. Lab. Xeol. Laxe, 5: 381-393

Coudé-Gaussen, G. (1978) - Confirmation de l'existence d'une glaciation wurmienne dans les montagnes du Nord-Ouest du Portugal. C. R. Somm. Soc. Géol. France, 1: 34-37

Coudé-Gaussen, G. (1979) - Les Serras da Peneda et do Gerês (Minho-Portugal). Formes et formations d'origine froide en milieu granitique. Thèse Univ, Paris I, 607 p.

Coudé-Gaussen, G. (1981)-Les Serras da Peneda et do Gerês. Étude géomorphologique, Memórias Centro de Estudos Geográficos, 5, Lisboa, 259 p.

Daveau, S. (1971) - La glaciation de la Serra da Estrela. Finisterra, (VI)11: 5-40.

Daveau.S; Devy-Vareta, N. (1985) - Gélifraction, nivation et glaciation d'abri de la Serra da Cabreira (Portugal). Actas da I Reun. Quat. Ibérico, Lisboa, I: 75-84.

Dias, G.; Leterrier, J.; Mendes, A.; Simôes, P. P.; Bertrand, J. M. (1998) - U-Pb zircon and monazite geochronology of post-collisional Hercynian granitoids from the Central Iberian Zone (Northern Portugal). Lithos, 45: 349-369.

Dreimanis, A. (1988) - Tills: their genetic terminology and classification. In R. P. Goldthwait e C. L. Matsch (eds), Genetic classification of glacigenic deposits, Balkema, Rotterdam, 17-83.

Duplessy, J. C.; Delibrias, G.; Turon, J. L.; Pujol, C; Duprat, J. (1981) - Deglacial warming of the Northeastern Atlantic Ocean: correlation with the paleoclimatic evolution of the European Continent. Paleog., Paleocl., Paleoec., 35: 121-144.

DupraT, J. (1983) - Les foraminifères planctoniques du Quaternaire terminal d'un domaine pericontinental (Golfe de Gascogne, Côtes Ouest-Ibériques, Mer d'Alboran): écologie-biostratigraphie. Bull. Inst. Géol. Bassin d'Aquitaine, 33: 71-150.

Ferreira, A. B.; Vidal-Romani, J. R.; Vilaplana, J. M.; Rodrigues, M. L.; ZêZere, J. L.; Monge, C. (1992) - Formas e depósitos glaciários e periglaciários da Serra do Gerês-Xurés (Portugal; Galiza). Levantamento cartográfico. Cuad. Lab. Xeol. Laxe, 17: 121-135.

Ferreira, A. B.; Vidal-Romaní, J. R.; ZÊZere, J. L.; Rodrigues, M.L. (1999) - A glaciação plistocénica da Serra do Gerês. Vestígios geomorfológicos e sedimentológicos. A.G.F.A., Rel. 37, Centro de Estudos Geográficos, Lisboa, 150 p.

Frenzel, B.; Pécsi, M.; Velichko, A. A. (eds.) (1992)-Atlas of Paleoclimates and Paleoenvironments of the Northern Hemisphere, Late Pleistocene-Holocene. Geogr. Res. Inst., Hungarian Acad. of Sc., Budapest, 153 p. 
GARCIA-SAINZ, L. (1950) - L'origine des glaciers ibériques quaternaires et la trajectoire cyclonale de l'Atlantique. C. R. Congrès. Int. Géogr. Lisbonne, II, 722-730.

GIRÃo, A. (1958) - Glaciação quaternária na Serra do Jurês. Bol. Centro Est. Geog., 16/17: $13-22$.

GoDARD, A. (1972) - Quelques enseignements apportés par le Massif Central français dans l'étude géomorphologique des socles cristallins. Rev. Géog. phys. Géol. dyn., XIV: 265-296.

Grandal, A.; Lopez Gonzalez, F.; Vidal Romaní, J. R. (1997) - Condicionantes en la distribucion de macromamíferos en Galicia (NW Península Ibérica) durante el Cuaternario superior. Cadernos Lab. Xeolóxico de Laxe, 22: 43-66.

Gutiérrez Sanchez, G. (1957) - Notas sobre la Sierra de Xurés (Ourense). Not. y Com. Inst. Geol. Min. España, 27-36.

Hernández-Pacheco, F. (1957) - El glaciarismo cuaternario de la Sierra de Queija. Bol. R. Soc. Esp. Hist. Nat., S. Geol., LV: 27-74.

Jorge, R. (1888) - As caldas do Gerez. O Gerez, thermal. Porto, 176 p.

Lautensach, H. (1929) - Eiszeitstudien in der Serra da Estrela (Portugal). Zeits. f. Gletscherkunde, XVII: 324-369. Trad. port.: Estudo dos glaciares da Serra da Estrela, in Memórias e Notícias, 1932, VI: 1-60.

Martínez De Pisón, E.; Arenillas Parra, M. (1979)-Algunos problemas de morfología glaciar en la España atlántica. Acta. Geol. Hisp., 14: 445-450.

Martínez De Pisón, E.; Arenillas Parra, M. (1984) - Nuevos problemas de morfología glaciar en la España atlántica. Est. Geogr., 175: 159-174.

Martins, J. A. (1972) - Les roches granitiques rouges de la Serra do Gerês (Région Nord

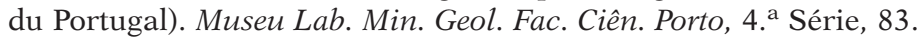

Moreira, A.; Ramos, J. M. F. (1981) - Vestígios de glaciação na Serra da Peneda (Noroeste de Portugal). Com. Serv. Geol. Port., 67: 95-98.

Moreira, A.; Ribeiro, M. L. (1991) - Carta Geológica do Parque Nacional da Peneda Gerês, Esc. 1/50.000. Notícia Explicativa. Serv. Geol. Port. e Parque Nac. Peneda-Gerês, 57 p.

Noronha, F.; Ribeiro, M. L. (1983) - Carta Geológica de Portugal. Notícia Explicativa da Folha 6-A, Montalegre. Serv. Geol. Portugal, Lisboa, 30 p.

Pérez Alberti, A.; Guitián Rivera, L.; Valcárcel Díaz, M. (1993) - Las formas y depósitos glaciares en las Sierras Orientales y Septentrionales de Galicia (NW Península Ibérica). In Pérez Alberti, Guitián Rivera e Ramil Rego (Eds.), La evolución del paisaje en las Montañas del entorno de los Caminos Jacobeos, Xunta de Galicia, p. 61-90.

Perttunen, M.; Hirvas, H. (1982) - An attempt to use the roundness of quartz grains for till stratigraphy. Bull. Geol. Soc. Finland, 54: 25-33.

Pujol, C. (1980)-Les foraminifères planctoniques de l'Atlantique Nord au Quaternaire. Écologie, Stratigraphie, Environnement. Mémoires Inst. Géol. Bassin d'Aquitaine, 10, Bordeaux, $254 \mathrm{p}$.

Ramil Rego, P.; Aira Rodríguez, M.J.; Alonso Mattias, F. (1995) - Caracterización climática y vegetacional de la Serra de Gerês (Portugal) durante el Tardiglaciar y el Holoceno: análisis polínico de A Lagoa do Marinho. Actas 3. ${ }^{a}$ Reun. Quat. Ibérico, Coimbra, 1993, $85-92$. 
Ruddiman, W. F.; McIntyre, A. (1981) - The North Atlantic Ocean during the last deglaciation. Paleog., Paleocl., Paleoec., 35: 145-214.

Schмidт-Tномé, P. (1973)-Neue, niedrig gelegene Zeugen einer würmeiszeitlichen Vergletscherung in Nordteil der Iberischen Halbinsel (Prov. Vizcaya und Orense in Nordspanien; Minho-Distrikt in Nordportugal). Eiszeitalter u. Gegenwart, 23/24: 384-389.

Schmidt-Thомé, P. (1978) - Nuevos testigos de una glaciación wurmiense extensa y de altura muy baja en el Noroeste da la Península Ibérica (Orense, España y Minho/Trás-os-Montes, Portugal). Cuad. Sem. Est. Cerám. Sargadelos, 37: 221-243.

Schмiтz, H. (1969) - Glazialmorphologische Untersuchungen im Bergland Nordwestspaniens (Galicien/León). Kölner Geogr. Arb., Heft 23, 157 p.

Teixeira, C.; Cardoso, J. L. (1979) - A não confirmação de fenómenos glaciários nas montanhas do Norte de Portugal (Peneda-Gerês). Bol. Soc. Geol. Portugal, 21: 163-184.

Twidale, C. R. (1982) - Granite Landforms. Elsevier, Amsterdam, 372 p.

Valadas, B. (1984) - Les Hautes Terres du Massif Central Français. Contribution à l'étude des morphodynamiques récentes sur les versants cristallins et volcaniques. Thèse Doctorat d'État, Paris-Sorbonne, 927 p.

Valcárcel Díaz, M.; Pérez Alberti, A. (1998) - Límite máximo de la glaciación y línea de equilibrio glaciar en el Noroeste da la Península Ibérica durante el último periodo frío. In A. Gómez Ortiz e F. SALVAdor Franch (eds), Investigaciones recientes de la Geomorfología española, Barcelona: 455-462.

Van Der Knapp, W. O.; Van Leeuwen, J. F. N. (1997) - Late Glacial and early Holocene vegetation succession, altitudinal vegetation zonation, and climate change in the Serra da Estrela, Portugal. Review of Paleobotany and Palynology, 97: 239-285.

Van Der Meer, J. J. M. (1987) - Micromorphology of glacial sediments as a tool in distinguishing genetic varieties of till. Geol. Surv. Finland. Special Paper, 3: 77-89.

Vidal Romani, J. R. (1989) - Geomorfología granítica en Galicia (NW España). Cuad. Lab. Xeol. Laxe, 13: 89-163.

Vidal Romani, J. R.; Brum Ferreira, A.; ZêZere, J. L.; Rodrigues, M. L.; Monge, C. (1990 a) - Evolución cuaternaria del relieve granítico en la Serra de Gerês-Xurés (Minho, Portugal-Ourense, Galicia). Cuaternario y Geomorfología, 4: 3-12.

Vidal Romani, J. R.; Vilaplana, J. M.; Brum Ferreira, A.; ZêZere, J. L.; Rodrigues, M. L.; Monge, C. (1990 b) - Los tills de la Serra de Gerês-Xurés y la glaciación pleistocena (Minho, Portugal-Ourense, Galicia). Cuaternario y Geomorfología, 4: 13-25.

Vidal Romaní, J. R.; SANTOS , L. (1994) - La deglaciación finicuaternaria en el NW peninsular, Sierra de Queixa, Orense. Datos geomorfológicos y paleobotánicos. Cuaternario y Geomorfología, 8: 33-44.

Vidal Romani, J. R.; SAntos FidAlgo, L.; JaLut, G. (1995) - Cronología relativa del máximo glaciar finipleistoceno en el sector Nor-Oriental de la Serra de Queixa (Ourense, Galicia, España). Actas 3. ${ }^{a}$ Reun. Quat. Ibérico, Coimbra (1993), 215-222.

Vidal Romaní, J. R.; Fernandez Mosquera, D.; Marti, K.; Brum Ferreira, A. (1999) - Nuevos datos para la cronología glaciar pleistocena en el NW de la Península Ibérica. Cadernos Lab. Xeolóxico de Laxe, 24: 7-29. 